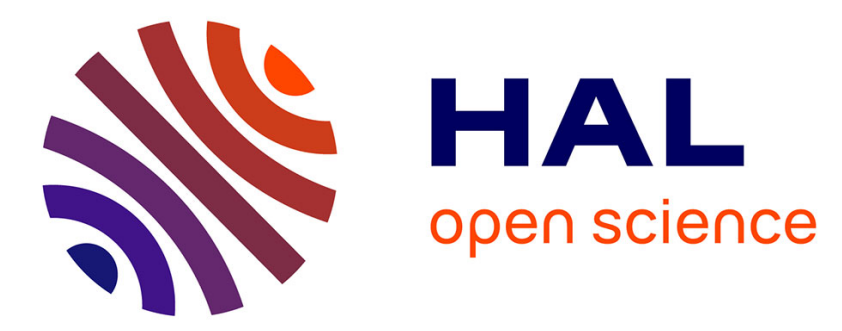

\title{
Interplay Between Charge Accumulation and Oxygen Reduction Catalysis in Nanostructured TiO2 Electrodes Functionalized with a Molecular Catalyst
}

Yee-seul Kim, Alla G. Bessmertnykh-Lemeune, Sébastien Kriegel, Kenneth D Harris, Benoît B Limoges, Véronique Balland

\section{To cite this version:}

Yee-seul Kim, Alla G. Bessmertnykh-Lemeune, Sébastien Kriegel, Kenneth D Harris, Benoît B Limoges, et al.. Interplay Between Charge Accumulation and Oxygen Reduction Catalysis in Nanostructured TiO2 Electrodes Functionalized with a Molecular Catalyst. ChemElectroChem, In press, 10.1002/celc.202100424 . hal-03272209

\section{HAL Id: hal-03272209 \\ https://hal.science/hal-03272209}

Submitted on 5 Jul 2021

HAL is a multi-disciplinary open access archive for the deposit and dissemination of scientific research documents, whether they are published or not. The documents may come from teaching and research institutions in France or abroad, or from public or private research centers.
L'archive ouverte pluridisciplinaire HAL, est destinée au dépôt et à la diffusion de documents scientifiques de niveau recherche, publiés ou non, émanant des établissements d'enseignement et de recherche français ou étrangers, des laboratoires publics ou privés. 


\title{
Interplay between charge accumulation and oxygen reduction catalysis in nanostructured $\mathrm{TiO}_{2}$ electrodes functionalized with a molecular catalyst
}

\author{
Yee-Seul Kim, ${ }^{[a]}$ Sébastien Kriegel, ${ }^{[a]}$ Alla Bessmertnykh-Lemeune, ${ }^{[b]}$ Kenneth D. Harris, ${ }^{[c]}$ Benoît \\ Limoges, ${ }^{*[a]}$ and Véronique Balland ${ }^{*[a]}$
}
[a] Dr. Y-S Kim, Dr. S. Kriegel, Dr. B. Limoges and Dr. V. Balland
Université de Paris, Laboratoire d'Electrochimie Moléculaire, UMR 7591, CNRS, F-75013 Paris, France
E-mail: limoges@u-paris.fr, veronique.balland@u-paris.fr
[b] Dr. A. Bessmertnykh-Lemeune
ENS de Lyon, UMR 5182, CNRS, Université Claude Bernard Lyon 1, Laboratoire de Chimie, 69342 Lyon, France
[c] Dr. K.D. Harris
NRC Nanotechnology Research Centre, Edmonton, Alberta T6G 2M9, Canada
\& Department of Mechanical Engineering, University of Alberta, Edmonton, Alberta T6G 2V4, Canada

\begin{abstract}
The catalytic reduction of $\mathrm{O}_{2}$ by a manganese(III) porphyrin immobilized in a nanostructured semiconductive transparent $\mathrm{TiO}_{2}$ electrode is here investigated by UV-Vis spectroelectrochemistry in an aqueous buffered medium. Analysis of the operando spectroelectrochemical data, collected for both the immobilized catalyst and the $\mathrm{TiO}_{2}$ matrix, demonstrates the coexistence of two faradaic electrochemical processes, namely (I) irreversible interfacial electron transfer from $\mathrm{TiO}_{2}$ to the immobilized porphyrin triggering the catalytic reduction of $\mathrm{O}_{2}$, and (ii) reversible proton-coupled electrochemical reduction of $\mathrm{TiO}_{2}$ leading to the accumulation of electrons in the $\mathrm{TiO}_{2}$ bulk. The competition between these two processes is modulated by the local concentration of $\mathrm{O}_{2}$, which itself varies with the rate of the catalysis. Indeed, when $\mathrm{O}_{2}$ is locally strongly depleted by catalysis, the process switches from catalysis to charge storage, like a battery. As a result, the electrons stored in $\mathrm{TiO}_{2}$ were observed to pursue the catalysis even after the electrode polarization was switched-off (i.e., under open circuit). This is an overlooked phenomenon that we believe is important to consider in applications relying on metal oxide-based photoelectrodes operating in aqueous media.
\end{abstract}

\section{Introduction}

Titanium dioxide is an inexpensive wide band-gap semiconductive material characterized by good transparency in the visible as well as robust photochemical stability. $\mathrm{TiO}_{2}$ can also be easily shaped to prepare nanostructured transparent electrodes with large specific surface areas. These electrodes have proven particularly useful in a wide range of applications from dye-sensitized solar cells to electrochromic windows, sensors or photoelectrocatalytic systems. ${ }^{[1-3]}$ In the field of photoelectrocatalytic applications, $\mathrm{TiO}_{2}$ was used as both photosensitizer (in the UV-range) and catalyst, as demonstrated in the early 1970 s for water splitting, ${ }^{[4]}$ but also later for $\mathrm{O}_{2}, \mathrm{~N}_{2}$ and $\mathrm{CO}_{2}$ photoelectroreduction in aqueous media. ${ }^{[5,6]}$ These seminal works opened decades of research to improve the performances of $\mathrm{TiO}_{2}$-based photoelectrocatalytic devices, notably for fuel conversion and preparation of chemical building blocks. ${ }^{[7-9]}$
One of the strategies commonly used to improve the performance of such devices is to immobilize a redox-active co-catalyst on porous $\mathrm{TiO}_{2}$-based nanostructured photoelectrodes. ${ }^{[10,11]}$ Among the assortment of molecular co-catalysts that have been investigated, those based on synthetic coordination complexes are of particular interest because their reactivity can be modulated by fine-tuning their coordination spheres. This process grants access to more selective photoelectrocatalytic reactions under milder experimental conditions. ${ }^{[12,13]}$ In addition, because molecular catalysts are characterized by specific electronic transitions that are sensitive to the metal ion redox and coordination states, many of them can be monitored by UV-Vis absorption spectroelectrochemistry under operando conditions, which is particularly useful for identifying the nature of electrogenerated species as well as transient intermediates. ${ }^{[14,15]}$ For efficient charge transfer and long-term operation, however, chemical immobilization is required as a stable monolayer directly at the $\mathrm{TiO}_{2}$ surface. Among the different immobilization methods so far proposed, those based on the chemisorption of a phosphonate anchoring group to $\mathrm{TiO}_{2}$ have proven quite effective, ${ }^{[16-20]}$ especially when working in mild aqueous media. Furthermore, due to the high surface area of the mesoporous or nanostructured $\mathrm{TiO}_{2}$ electrodes, which allows for high catalyst loading, the as-modified electrodes are well-suited for simple and sensitive monitoring by UV-Vis absorption spectroelectrochemistry. ${ }^{[21]}$ Another key advantage of this methodology is that it provides immediate quantitative information on the amount of immobilized electroactive chromophore/catalyst, including the possibility to follow its fate during the photoelectrochemical process operando. ${ }^{[18,22]}$ By identifying reactive intermediates, $\mathrm{TiO}_{2}$ modified with anchored molecular catalysts can also lead to significant insights regarding the catalytic mechanisms, as previously demonstrated for immobilized Re and Mn molecular catalysts under steady-state turnover conditions. ${ }^{[16,17]}$ In addition, the millisecond time resolution achieved by the cyclic voltabsorptometry or chronoabsorptometry techniques allows relevant kinetic information to be obtained on the interfacial electron transfer with the immobilized redox-active chromophore. ${ }^{[23,24]}$ 
Beyond the characterization of immobilized molecular chromophore/catalyst, UV-Vis spectroelectrochemistry is also well-suited for monitoring charge accumulation in the semiconductive $\mathrm{TiO}_{2}$ material. Indeed, as initially demonstrated by Fitzmaurice and coll., a blue coloration is observed when a negative potential is applied to $\mathrm{TiO}_{2} \cdot{ }^{[25,26]}$ This is attributed to the accumulation of electrons within the conduction band and localized states of the metal oxide, rendering the $\mathrm{TiO}_{2}$ increasingly conductive until it becomes fully degenerate and acts as a metallike conductive film for applied potentials above the conduction band potential $\left(E_{\mathrm{CB}}\right){ }^{[27]}$ The exact origin of the blue coloration is, however, still under debate. The main hypotheses that have been put forward are that the blue coloration results either from

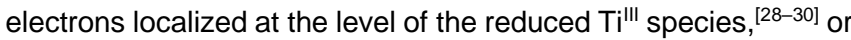
from free electrons delocalized in the band-gap, ${ }^{[31]}$ or from the coexistence of both. ${ }^{[32]}$ In aqueous media, charge accumulation in $\mathrm{TiO}_{2}$ occurs according to a proton-coupled process as attested by the $-60 \mathrm{mV}$ per pH unit dependence of the $\mathrm{TiO}_{2}$ flatband potential over a very large $\mathrm{pH}$-range. ${ }^{[33]}$ Proton uptake was also evidenced with photoreduced $\mathrm{TiO}_{2}$ nanoparticles in both aqueous and protic organic solutions, ${ }^{[34,35]}$ thus offering novel prospects for use as proton-coupled electron transfer reagents for the reduction of various substrates. ${ }^{[36,37]}$ For a long time, this proton-coupled charge storage process was assumed to be limited to a nearsurface region, and it is only recently that it was demonstrated to occur within the bulk of nanostructured $\mathrm{TiO}_{2}$ electrodes, notably in buffered as well as unbuffered mild aqueous electrolytes containing Brønsted weak acids (i.e. proton donors). ${ }^{[38-40]}$

To date, little is known about electrochemical charge accumulation in $\mathrm{TiO}_{2}$ under catalytic turnover conditions, except in a work published by Reisner's group mentioning a lower steady-state concentration of electrons in the conduction band under catalytic production of $\mathrm{H}_{2}$ by an immobilized $\mathrm{Ni}(\mathrm{II})$ bis(diphosphine) catalyst. ${ }^{[18]}$ The interplay between the catalytic processes and the charge storage processes within modified semiconductive $\mathrm{TiO}_{2}$ matrices thus remains largely overlooked, despite its potentially significant consequences in photoelectrocatalytic applications. The purpose of the present study is thus to fill this gap. To contribute to this field, we have taken advantage of mesoporous $\mathrm{TiO}_{2}$ electrodes made of an amorphous nanostructured film of $\mathrm{TiO}_{2}(0.55 \mu \mathrm{m}$ thick $)$ deposited by glancing angle deposition (GLAD) over a flat transparent conductive substrate of indium tin oxide (ITO) on glass. ${ }^{[41]}$

The nanostructured film forming these electrodes is characterized by an array of $\mathrm{TiO}_{2}$ nanocolumns oriented perpendicularly to the substrate. This morphology allows for fast diffusion of species throughout the entire thickness and porosity of the film. These electrodes have also been thoroughly characterized in previous works for their proton-coupled electron charge storage properties in aqueous buffered electrolytes. ${ }^{[38]}$ As a molecular catalyst, we have chosen $\mathrm{Mn}(\mathrm{III})$ porphyrin $\mathbf{M n}-\mathbf{P}$ substituted with one phosphonate group in the meso position of the macrocycle. This is useful to establish firm chemisorptive anchoring of the porphyrin to the metal oxide surface, ${ }^{[42,43]}$ most likely here in a bidentate mode. ${ }^{[44]}$

$\mathrm{Mn}$ (III) porphyrins are characterized by intense light absorption bands in the visible region, which are distinct from the spectroscopic features of the reduced $\mathrm{TiO}_{2}$. The position and magnitude of these bands are also highly sensitive to both the redox state and first coordination sphere of the metal-ion. It is thus well-suited for UV-Vis spectroelectrochemical studies.
Manganese porphyrins are also well recognized for their ability to catalyze the reduction of $\mathrm{O}_{2}$ into water, in both organic and aqueous solutions. ${ }^{[45-48]}$ Finally, we present here a spectroelectrochemical analysis of transparent nanostructured GLAD- $-\mathrm{TiO}_{2}$ electrodes modified with a manganese porphyrin under both catalytic and non-catalytic conditions (i.e., in the presence and absence of $\mathrm{O}_{2}$ ) in an aqueous buffered medium. By systematically comparing the data obtained with this modified electrode to those collected at a nanostructured GLAD-ITO electrode modified by the same catalyst, we highlight the specificities induced using a semiconductive $\mathrm{TiO}_{2}$ film instead of a fully conductive electrode such as ITO.
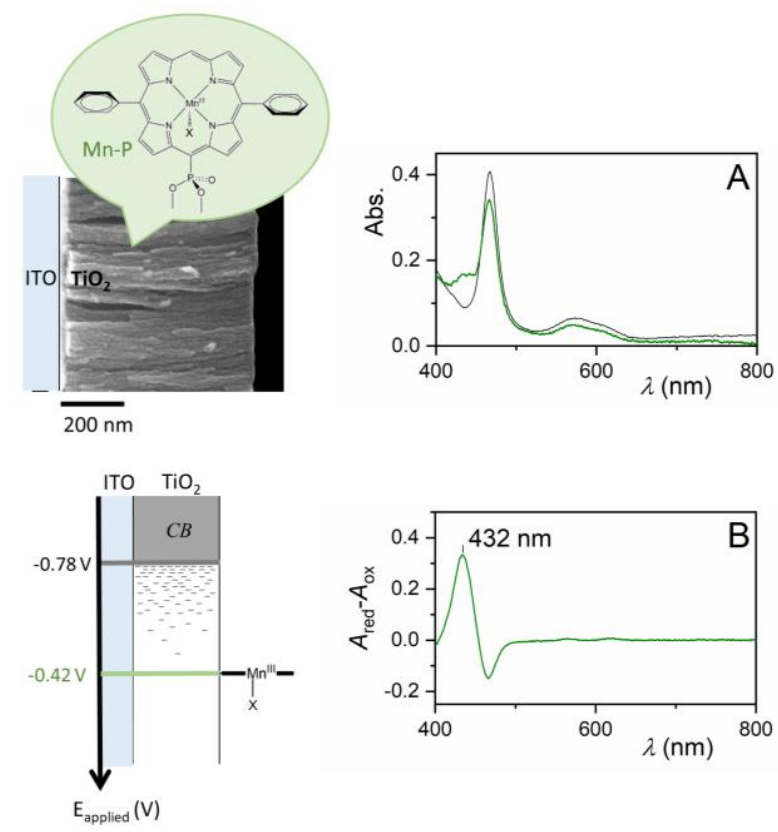

Figure 1. (Top) Schematic representation of the Mn-P/GLAD-TiO 2 electrode (with $\mathrm{X}=\mathrm{H}_{2} \mathrm{O}$ in aqueous electrolytes) and (bottom) associated electronic description. (A) UV-Vis absorption spectra (corrected for the GLAD-TiO 2 contribution) recorded for (green) the as-prepared $\mathrm{Mn}-\mathrm{P} / \mathrm{GLAD}-\mathrm{TiO}_{2}$ and (black) a homogeneous $25 \mu \mathrm{M}$ Mn-P solution (in a 1:9 DMSO:water mixture added in a quartz cell of $1 \mathrm{~cm}$ path length). (B) Difference spectrum obtained by subtracting the spectra recorded at a Mn-P/GLAD-TiO 2 electrode polarized at +0.5 and -0.8 $\mathrm{V}$ vs. Ag/AgCl.

\section{Results and Discussion}

Manganese(III) porphyrinylphosphonate $\mathbf{M n - P}$ was prepared from the free base porphyrin $\mathbf{2 H}-\mathbf{P}-\mathrm{Et}$ according a two step procedure (Scheme 1).

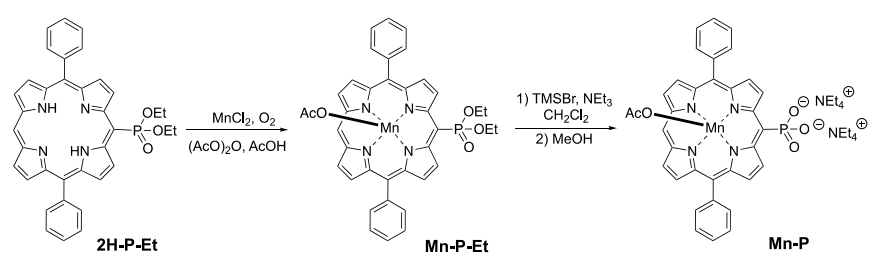

Scheme 1. Synthesis of Mn-P. 
Firstly, insertion of the metal ion in the macrocycle was achieved by refluxing the porphyrin $2 \mathrm{H}-\mathrm{P}$-Et with anhydrous $\mathrm{MnCl}_{2}$ in acetic acid in the presence of acetic anhydride for 4 hours. The complex Mn-P-Et thus obtained was treated with an excess of $\mathrm{TMSBr}$ followed by addition of methanol to prepare ammonium salt of the target porphyrinylphosphonate Mn-P. The complexes Mn-P-Et and $\mathbf{M n}-\mathbf{P}$ were characterized by HR-ESI spectrometry, IR and UV-Vis spectroscopies, with the last one being the most useful spectroscopic technique for the study of manganese porphyrins (see Figure S1 and associated comment). The complex Mn-P bearing the phosphonate anchoring group is soluble in polar organic and aqueous media, which is useful for material preparation. It is worth noting, that the axial ligands of Mn(III) porphyrins are easily replaced by water molecules in aqueous media. ${ }^{49]}$

Nanostructured films of $\mathrm{TiO}_{2}$ (550 nm thick, amorphous) and ITO (500 nm thick) were deposited onto planar ITO electrodes as previously described (see Experimental Section for details and Figure S2 for SEM images). These electrodes are characterized by surface enhancements of 300 and 35 , for $\mathrm{TiO}_{2}$ and ITO respectively. ${ }^{[22]}$ Further modification of the electrodes with the porphyrin catalyst was achieved by soaking the GLAD electrodes overnight in a $25 \mu \mathrm{M}$ aqueous solution of $\mathbf{M n}-\mathbf{P}$. After thorough rinsing, the resulting modified Mn-P/GLAD electrodes (see Figure 1 for a schematic representation) were investigated by cyclic voltabsorptometry in HEPES buffered electrolyte solution (solution of $0.05 \mathrm{M} \mathrm{Na}_{2} \mathrm{SO}_{4}$ and $0.1 \mathrm{M}$ HEPES, pH 7.0). The spectroelectrochemical features of the Mn-P/GLAD-TiO electrode under argon at $0.1 \mathrm{~V} \cdot \mathrm{s}^{-1}$ are shown in Figure 2 (green lines). The cyclic voltammogram (CV) is characterized by a reversible exponential rise of the current when the applied potential is scanned below $E \sim-0.6 \mathrm{~V}$, while the concomitantly recorded cyclic voltabsorptogram at $780 \mathrm{~nm}\left(\mathrm{CVA}_{780}\right)$ shows a reversible absorbance increase (reversible blue coloration). These characteristics are typical of reversible switching of the mesoporous $\mathrm{TiO}_{2}$ semiconductor film between an insulating and a conductive state..$^{[2,50]}$ As the applied potential rises towards the conduction band potential $E_{\mathrm{CB}}$ (estimated to be $-0.78 \mathrm{~V}$ vs. $\mathrm{Ag} / \mathrm{AgCl}$ at $\mathrm{pH} 7.0$ ), the $\mathrm{TiO}_{2}$ film conductivity progressively increases due to the filling of states within the conduction band as well as localized electronic states within the bandgap. ${ }^{[23,25]}$ Once fully conductive, the nanostructured $\mathrm{TiO}_{2}$ film behaves as a metallike conductive electrode, with a large electrical double-layer capacitance directly proportional to the enhanced electrode surface area. Furthermore, in buffered electrolytes, this current rise includes an additional contribution from the reversible electrochemical reduction of the lattice $\mathrm{Til}^{\mathrm{iV}}$ ions in $\mathrm{TiO}_{2}$. This faradaic process is coupled with the concomitant insertion of protons within the bulk $\mathrm{TiO}_{2}$ to compensate the injected negative charge. ${ }^{[38]}$ The protons are provided by the weak acid of the buffer system, leading in CV to a characteristic pair of broad reversible faradaic peaks centered on an apparent formal potential of $E^{\circ}{ }_{\text {TiO2/TiOOH }}=-1.06 \mathrm{~V}$ vs. $\mathrm{Ag} / \mathrm{AgCl}$ at $\mathrm{pH} 7.0 .{ }^{[38]} \mathrm{This}$ faradaic proton-coupled electron transfer reaction imposed on top of the capacitive background current can also be written as follows:

$\mathrm{Ti}^{\prime V} \mathrm{O}_{2}+x \mathrm{e}^{-}+x \mathrm{AH} \leftrightarrows \mathrm{Ti}^{\mathrm{IV}}{ }_{1} x \mathrm{Ti}^{\prime \prime \prime} x(\mathrm{O})_{1} x(\mathrm{OH}) x+x \mathrm{~A}^{-}$

where $\mathrm{AH}$ and $\mathrm{A}^{-}$are the acid and the conjugate base of the HEPES buffer, respectively, and $x$ the maximal amount of protons

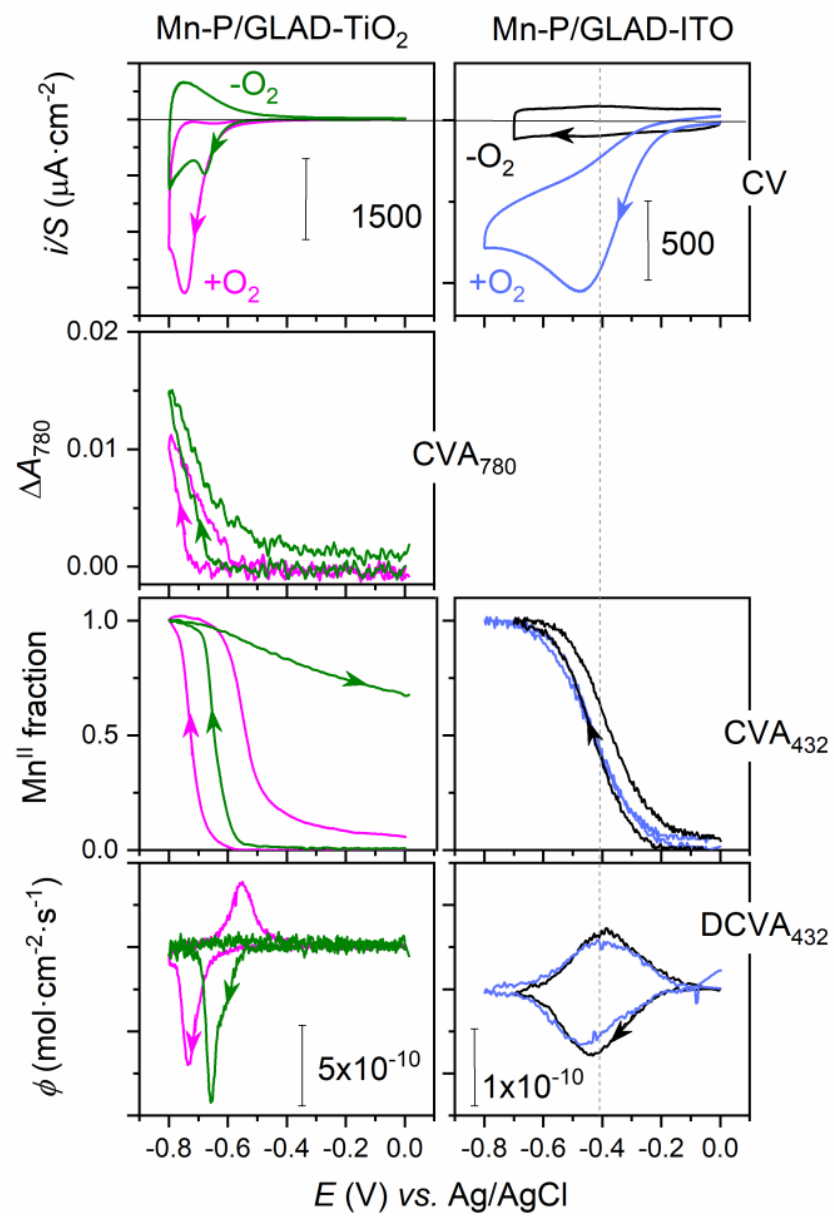

Figure 2. Spectroelectrochemical features recorded at (left) $\mathrm{Mn}-\mathrm{P} / \mathrm{GLAD}-\mathrm{TiO}_{2}$ and (right) $\mathrm{Mn}-\mathrm{P} / \mathrm{GLAD}-\mathrm{ITO}$ electrodes. The (top) $\mathrm{CVs}$ and concomitantly monitored (middle) CVAs (at either 780 or $432 \mathrm{~nm}$ ) were recorded at $v=0.1$ $\mathrm{V} \cdot \mathrm{s}^{-1}$. The (bottom) DCVAs are the first derivatives of the CVAs at $432 \mathrm{~nm}$. The experiments were conducted under (green and black) argon and (magenta and blue) saturated $\mathrm{O}_{2}$ atmospheres. In the $\mathrm{CVA}_{432}$, the $\mathrm{Mn}^{\mathrm{II}}-\mathrm{P}$ surface coverage was normalized to $\Gamma^{0}$ to allow for a better comparison of the data obtained with the GLAD-TiO 2 and GLAD-ITO electrodes (each characterized by different surface coverage of $\mathrm{Mn}-\mathrm{P}$, i.e. $\Gamma^{0}=5.0 \times 10^{-10}$ and $1.5 \times 10^{-10} \mathrm{~mol} \cdot \mathrm{cm}^{-2}$, respectively). Experiments were conducted at $25^{\circ} \mathrm{C}$ in a $0.1 \mathrm{M} \mathrm{HEPES}$ buffer + $0.05 \mathrm{M} \mathrm{Na}_{2} \mathrm{SO}_{4}$ at $\mathrm{pH} 7.0$.

which can be reversibly stored within the $\mathrm{TiO}_{2}$ lattice (previously established to $x=0.45$ for the amorphous $\mathrm{GLAD}-\mathrm{TiO}_{2}$ electrodes). ${ }^{[39,40]}$

In the $\mathrm{CV}$ of the Mn-P/GLAD-TiO 2 electrode, a small sharp and irreversible cathodic peak is also detected at $E=-0.68 \mathrm{~V}$. Its attribution to the $\mathrm{Mn}^{\mathrm{III}} \rightarrow \mathrm{Mn}^{\mathrm{I}}$ reduction of the immobilized chromophore can only be definitely assessed from the simultaneous absorbance increase at $432 \mathrm{~nm}$, a wavelength corresponding to the maximal absorbance difference between the light absorption bands of reduced and oxidized $\mathbf{M n - P}$ (see Figure $1 \mathrm{~B})$. It is worth noting, the intensive Soret band of $\mathrm{Mn}(\mathrm{II})$ porphyrins is obviously observed at $425-435 \mathrm{~nm} \cdot{ }^{[51]}$ The irreversibility of this electrochemical reduction process is confirmed from the very slow absorbance decay during the backward $\mathrm{CVA}_{432}$ scan. Such an irreversible interfacial electron transfer is characteristic of what has been previously reported for other porphyrins physisorbed in mesoporous $\mathrm{TiO}_{2}$ films. ${ }^{[23,52]}$ This 
behavior results from the formal potential of $\mathbf{M n}-\mathbf{P}\left(E_{M n-P}^{0}\right)$ being located in a potential region where $\mathrm{TiO}_{2}$ is insulating (see Figure 1). The electrochemical reduction of the porphyrin can thus only be achieved once the applied potential approaches the conductive zone of $\mathrm{TiO}_{2}$ during the forward scan. This leads to the following irreversible electron transfer reaction:

$\mathrm{Mn}^{\prime \prime \prime}-\mathrm{P}+\mathrm{e}_{\mathrm{TiO} 2}^{-} \rightarrow \mathrm{Mn}^{\prime \prime}-\mathrm{P}$

(where $\mathrm{e}_{\mathrm{TiO} 2}$ corresponds to $\mathrm{TiO}_{2}$ electrons involved in the interfacial electron transfer with the porphyrin complex). The irreversibility of this electrochemical process is due to the fact that, during the reverse scan, the $\mathrm{TiO}_{2}$ film becomes insulating before reaching the $E^{0^{\prime}}$ Mn-P value. In the present case, the formal potential of $\mathbf{M n}-\mathbf{P}$ was estimated from the CV and $\mathrm{CVA}_{432}$ simultaneously recorded at the conductive Mn-P/GLAD-ITO electrode, showing a fully reversible redox transition (see black lines in Figure 2) at $E^{\prime}{ }_{M n-P}=-0.42 \mathrm{~V}$ (vs. Ag/AgCl).

This value is clearly significantly higher than the conduction band potential of $\mathrm{TiO}_{2}$ (i.e., $-0.78 \mathrm{~V}$ at $\mathrm{pH} 7.0$ ). Accordingly, at the $\mathrm{Mn}$ $\mathrm{P} / \mathrm{GLAD}-\mathrm{TiO}_{2}$ electrode, reduction of the immobilized chromophore can only be achieved at potentials much lower than $E^{\prime}{ }_{M n-P}$ (i.e., when the $\mathrm{TiO}_{2}$ is rendered sufficiently conductive). A quantitative analysis of the kinetics of this irreversible interfacial electron transfer reaction was achieved from the scan rate dependence of the derivative cyclic voltabsorptograms monitored at $432 \mathrm{~nm}\left(\mathrm{DCVA}_{432}\right.$ in Figure S3). Once expressed in flux density $\phi$ (in $\mathrm{mol} \cdot \mathrm{cm}^{-2} \cdot \mathrm{s}^{-1}$ ), their intensity is equivalent to the faradaic intensity obtained by CV (i.e., in absence of catalysis) on the basis of the following relationship:

$\phi=n \frac{d A_{\lambda}}{1000 \varepsilon_{\lambda} d t}=\frac{i_{f}}{F S}$

where $A_{\lambda}$ and $\varepsilon_{\lambda}$ are the Mn-P absorbance and extinction coefficients at the wavelength $\lambda, n$ the number of electrons involved in the redox transition (here $n=1$ for the $\mathrm{Mn}^{\text {III }} / \mathrm{Mn}^{\text {"I }}$ redox couple), $i_{f}$ the faradaic current contribution (in A), $F$ the Faraday constant (96 $485 \mathrm{C} \cdot \mathrm{mol}^{-1}$ ), and $S$ the geometric electrode area (in $\mathrm{cm}^{2}$ ).

The DCVA 432 were analyzed in the framework of our previous model, ${ }^{[23]}$ assuming fast electron transport across the $\mathrm{TiO}_{2}$ matrix as well as a fully irreversible heterogeneous electron transfer reaction between the immobilized porphyrin and the $\mathrm{TiO}_{2}$ electrode. Under these conditions, the following theoretical analytical expression of the irreversible faradaic peak can be used to fit the experimental data:

$\phi=k \Gamma^{0} \exp \left[-\alpha \frac{F}{R T}\left(E-E_{C B}\right)\right] \times \exp \left\{-\frac{R T}{\alpha F v} k \Gamma^{0}\left[-\alpha \frac{F}{R T}\left(E-E_{C B}\right)\right]\right\}$

where $E_{C B}$ is the conduction band edge potential of $\mathrm{TiO}_{2}$ (in V), $E$ is the applied potential (in $\mathrm{V}$ ), $T$ is the temperature (in $\mathrm{K}$ ), $v$ is the scan rate (in $\mathrm{V} \cdot \mathrm{s}^{-1}$ ), $\Gamma^{0}$ is the total surface coverage of the redox chromophore (in $\mathrm{mol} \cdot \mathrm{cm}^{-2}$ ), $\alpha$ is a parameter reflecting the distribution of localized states below the conduction band contributing to the interfacial electron transfer, and $k$ (in s $\mathrm{s}^{-1}$ ) is a first order electron transfer rate constant characterizing the interfacial electron transfer kinetics between electrons in the conduction band of $\mathrm{TiO}_{2}$ and the immobilized porphyrin. Eq. 4 was successfully fitted to the experimental DCVA 432 in Figure $S 3$, from which the following set of parameters was recovered: $k=272 \mathrm{~s}^{-1}$, and $\alpha=0.9$. The value of $\alpha$, close to 1 , indicates that the interfacial electron transfer mainly occurs from the conduction band, which is in line with what we previously reported at mesoporous anatase
$\mathrm{TiO}_{2}$ electrodes prepared from evaporation-induced selfassembly. ${ }^{[23]}$

Next, the modified GLAD- $-\mathrm{TiO}_{2}$ and -ITO electrodes were investigated under saturated $\mathrm{O}_{2}$ atmospheres. At both electrodes, intense and irreversible catalytic reduction peaks (magenta and blue lines in the $\mathrm{CV}$ of Figure 2), localized respectively at $-0.75 \mathrm{~V}$ and $-0.46 \mathrm{~V}$ for the $\mathrm{TiO}_{2}$ and ITO electrodes, are observed. The catalytic reduction of dioxygen at the Mn-P/GLAD- $\mathrm{TiO}_{2}$ is thus significantly downshifted in potential compared to the $\mathrm{Mn}$ P/GLAD-ITO, which is expected given that $\mathrm{TiO}_{2}$ has to reach a conductive state to reduce the $\mathbf{M n - P}$ catalyst, as discussed above. Furthermore, because the electron transfer at the $\mathrm{TiO}_{2}$ interface is irreversible, the reversibility of the $\mathrm{CVA}_{432}$ under $\mathrm{O}_{2}$ attests to the direct chemical reoxidation of the electrochemically reduced $\mathrm{Mn}$ "-P by $\mathrm{O}_{2}$. That $\mathrm{O}_{2}$ is catalytically reduced by $\mathbf{M n}-\mathbf{P}$ and not just directly reduced at the GLAD- $\mathrm{TiO}_{2}$ electrode was confirmed in a control experiment performed at a bare $\mathrm{GLAD}-\mathrm{TiO}_{2}$ electrode under the same experimental conditions (Figure S4). Indeed, a very sluggish reduction of $\mathrm{O}_{2}$ was observed in the $\mathrm{CV}$ (i.e., characterized by a small increase of the cathodic current at the end of the forward scan), while the corresponding $\mathrm{CVA}_{780}$ almost overlapped with the CVA recorded under argon. As a result, the contribution of direct $\mathrm{O}_{2}$ reduction at the $\mathrm{TiO}_{2}$ electrode can be considered as negligible.

At both modified electrodes, the peak shaped catalytic current response is indicative of a fast catalytic reaction, which rapidly becomes rate limited by the diffusional mass transport of $\mathrm{O}_{2}$ in solution (the concentration of which is $1.4 \mathrm{mM}$ under $1 \mathrm{~atm}$ of $\mathrm{O}_{2}$ at $25{ }^{\circ} \mathrm{C}$ ). This rate limitation was confirmed from the linear dependence of the catalytic peak intensities as a function of the square root of $v$ (Figure S5). In the case of the Mn-P/GLAD-TiO 2 electrode, the catalytic peak intensity was also observed to be independent of the catalyst coverage (at least within the surface concentration range explored) (Figure S5), which indicates an electrocatalytic reaction under total catalysis regime. Therefore, we can model this catalytic reaction as a simple fast bimolecular reaction $\left(k_{c a t}\right)$ between $\mathrm{O}_{2}$ and the reduced $M n^{\prime \prime}-\mathrm{P}$. The accumulation of the reduced catalyst at the Mn-P/GLAD-TiO ${ }_{2}$ electrode during the forward scan should thus result from a competition between: $(i)$ the irreversible electrochemical reduction of $\mathrm{Mn}^{\mathrm{III}}-\mathrm{P}$ by $\mathrm{TiO}_{2}$ and (ii) the chemical reoxidation of $\mathrm{Mn}^{\mathrm{II}}-\mathrm{P}$ by $\mathrm{O}_{2}$ according to the following rate equation:

$$
\frac{d \Gamma_{\mathrm{Mn}^{\mathrm{II}}}}{d t}=k\left(\Gamma^{0}-\Gamma_{\mathrm{Mn}}{ }^{\mathrm{II}}\right) \exp \left[-\alpha \frac{F}{R T}\left(E-E_{C B}\right)\right]-k_{c a t}\left[\mathrm{O}_{2}\right]_{z=0} \Gamma_{\mathrm{Mn}^{\mathrm{II}}}
$$

where $\Gamma_{\mathrm{Mn}}$ iI is the surface coverage of the reduced form of the immobilized catalyst, and $\left[\mathrm{O}_{2}\right]_{z=0}$ is the $\mathrm{O}_{2}$ concentration at the metal oxide/electrolyte interface. (Note that because the GLAD film thickness, i.e. $0.55 \mu \mathrm{m}$, is small relative to the thickness of the diffusion layer, $\delta_{\text {diff, }}$ we can approximate the mesoporous electrode as a very thin film located at $z=0$ with $\mathrm{O}_{2}$ diffusing from the bulk electrolyte to the metal oxide interface normal to the geometric electrode area. This geometry is depicted in Scheme 2.)

Information regarding the accumulation of the reduced form of the catalyst at the Mn-P/GLAD-TiO ${ }_{2}$ electrode under turnover conditions were retrieved from the $\mathrm{CVA}_{432}$ and $\mathrm{DCVA}_{432}$ summarized in Figure 2 and S5. At the reversal potential of -0.8 $\mathrm{V}$, one should note that the $432 \mathrm{~nm}$ absorbance is stable upon cycling as well as independent of $v$ (Figure S6). 


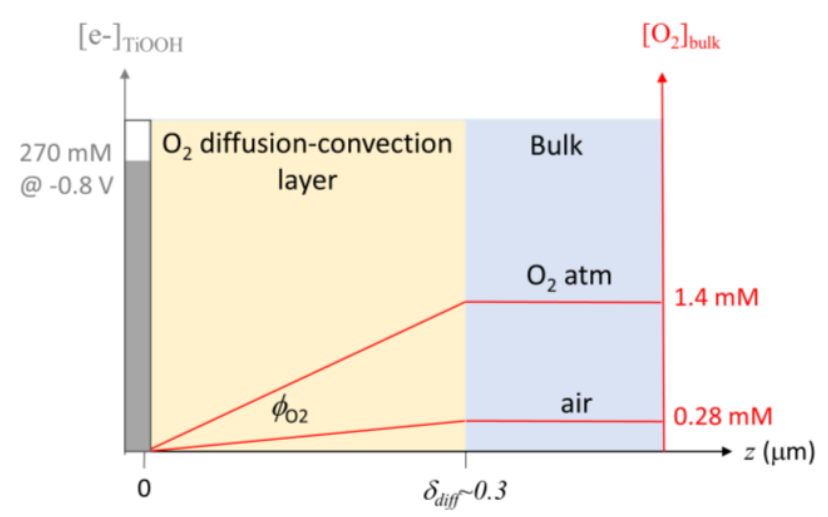

Scheme 2. Schematic representation of the mass transport and charge accumulation processes at the $\mathrm{Mn}-\mathrm{P} / \mathrm{GLAD}-\mathrm{TiO}_{2}$ electrode (symbolized by the grey bar which represents here the thickness of the porous electrode and its filling level in electrons, i.e. [ $\left.\left.\mathrm{e}^{-}\right]_{\mathrm{TiOOH}}\right)$ under reduced steady-state conditions.

Whatever the GLAD electrode, full accumulation of the reduced $\mathrm{Mn}$ "-P catalyst at the highest negative potentials is fully consistent with the total catalysis regime, which means that $\left[\mathrm{O}_{2}\right]_{z=0}$ is locally decreased to near-zero once the applied potential becomes sufficiently more negative than the catalytic peak potential. Therefore, only a negligible fraction of the catalyst (undetectable by spectroscopy) remains involved in the catalytic process to consume the incoming flux of $\mathrm{O}_{2}$. This leads to the $\mathrm{CVA}_{432}$ and $\mathrm{DCVA}_{432}$ recorded at the Mn-P/GLAD-ITO electrode being virtually unaffected by catalysis (i.e., no hysteresis compare the black and blue curves in Figure 2). This is not the case at the $\mathrm{Mn}-\mathrm{P} / \mathrm{GLAD}-\mathrm{TiO}_{2}$ electrode, where the $\mathrm{CVA}_{432}$ recorded under $\mathrm{O}_{2}$ (magenta line) and argon (green line) differ significantly (Figure 2). In particular, the following can be pointed out:

(i) a significant delay in the $432 \mathrm{~nm}$ absorbance increase during the forward scan under $\mathrm{O}_{2}$, leading to a downshift of the reduction peak in the corresponding $D_{C V A}{ }_{432}$ (offset of $-75 \mathrm{mV}$ from the irreversible DCVA peak potential, $E_{p}$, recorded under argon);

(ii) a significant hysteresis in the $\mathrm{CVA}_{432}$ under $\mathrm{O}_{2}$, leading to a large $\Delta E_{\mathrm{p}}$ value $\left(185 \mathrm{mV}\right.$ at $\left.0.1 \mathrm{~V} \cdot \mathrm{s}^{-1}\right)$ in the corresponding $\mathrm{DCVA}_{432}$. This hysteresis is strongly dependent on the scan rate, decreasing to $86 \mathrm{mV}$ at $5 \mathrm{mV} \cdot \mathrm{s}^{-1}$ (Figure S6).

These two observations illustrate the singular behavior of the Mn$\mathrm{P} / \mathrm{GLAD}-\mathrm{TiO}_{2}$ electrode compared to the Mn-P/GLAD-ITO, which is related to both the semiconductivity of the mesoporous matrix and also the ability of $\mathrm{TiO}_{2}$ to store a significant amount of charge via proton insertion-coupled electron transfer reduction of $\mathrm{TiO}_{2}$ (eq 1). Indeed, analysis of the $\mathrm{CVA}_{780}$ revealed that electron accumulation in $\mathrm{TiO}_{2}$ is significantly affected by the catalysis. First the $780 \mathrm{~nm}$ absorbance increase is delayed under turnover conditions (compare magenta and green curves in the $\mathrm{CVA}_{780}$ of Figure 2), starting to rise when the electrode potential lies below the catalytic peak potential. This indicates that electrons do not accumulate in $\mathrm{TiO}_{2}$ until $\mathrm{O}_{2}$ is locally depleted by catalysis (i.e., $\left[\mathrm{O}_{2}\right]_{z=0} \approx 0$ ). Second, the $A_{780}$ value reached at the reversal potential of $-0.8 \mathrm{~V}$ remains lower under turnover conditions than under argon, which is indicative of lower charge storage in $\mathrm{TiO}_{2}$. We assume that this is attributable to the steady consumption of electrons stored in $\mathrm{TiO}_{2}$ by the catalytic reaction that continues to slowly reduce incoming $\mathrm{O}_{2}$. It is worth noting here that these features are only observed in the presence of the immobilized catalyst and not at the bare GLAD- $\mathrm{TiO}_{2}$ electrode (Figure S4). The amounts of electrons stored in $\mathrm{TiO}_{2}$ at the point of the reversal potential was estimated to be $11 \mathrm{nmol} \cdot \mathrm{cm}^{-2}$ (per unit of geometric electrode area) under $\mathrm{O}_{2}$ (assuming $\varepsilon_{780}=1000 \mathrm{M}^{-1} \cdot \mathrm{cm}^{-1}$ ), a value much higher than the surface coverage of the immobilized porphyrin (which corresponds here to $\sim 0.5 \mathrm{nmol} \cdot \mathrm{cm}^{-2}$ ). Moreover, it is interesting to note that accumulation of the reoxidized $\mathrm{Mn}^{\text {III- }} \mathrm{P}$ catalyst during the backward scan only occurs once $A_{780}$ is close to zero, whatever the scan rate. Overall, these observations suggest a significant interplay between the charge storage in $\mathrm{TiO}_{2}$ and catalysis, modulated by the local concentration of $\mathrm{O}_{2}$, which itself varies with the rate of the catalysis and so with the applied potential.

In order to gain better insights into this specific reactivity, we performed complementary chronoabsorptometric experiments. Briefly, a cathodic potential of $E_{\text {cat }} \leq-0.80 \mathrm{~V}$ was applied for $15 \mathrm{~s}$ to the $\mathrm{Mn}-\mathrm{P} / \mathrm{GLAD}-\mathrm{TiO}_{2}$ electrode, followed either by relaxation under open circuit potential (OCP) or by a potential step at an anodic value of $E_{\mathrm{an}}=0 \mathrm{~V}$. Upon applying $E_{\text {cat }}$, we expect to induce a sufficiently fast electron transfer at the $\mathrm{TiO}_{2}$ interface, in such a way as to rapidly consume $\mathrm{O}_{2}$ by catalysis in the diffusion-reaction layer and so to reach $\left[\mathrm{O}_{2}\right]_{z=0} \approx 0 \mathrm{M}$. Given the $15 \mathrm{~s}$ reduction period, the $\mathrm{O}_{2}$ diffusion layer thickness $\delta_{\text {diff }}$ is expected to be $\sim 300 \mu \mathrm{m}\left(\delta_{\text {diff }} \approx\left(\pi D_{\mathrm{O}_{2}} t\right)^{1 / 2}\right)$, assuming a diffusion coefficient of $D_{\mathrm{O}_{2}}=2.4 \times 10^{-5} \mathrm{~cm}^{2} \cdot \mathrm{s}^{-1} \cdot{ }^{[53]}$ This $\delta_{\text {diff }}$ value is most likely close to the thickness imposed by the natural diffusion-convection layer. ${ }^{[54]}$ Accordingly, we expect a steady-state gradient of $\mathrm{O}_{2}$ concentration to be almost reached at the end of the reduction step, thus providing a constant incoming flux of $\mathrm{O}_{2}$ at the electrode interface as depicted in Scheme 2. This assumption is further supported by the current density asymptotically reaching an almost constant value after $15 \mathrm{~s}$ (Figure S7). Under such conditions, the flux of $\mathrm{O}_{2}$ arriving at the $\mathrm{TiO}_{2}$ interface is given by Fick's first law:

$\phi_{\mathrm{O}_{2}}=\frac{\partial\left[\mathrm{O}_{2}\right]_{z=0}}{\partial t}=D_{\mathrm{O}_{2}} \frac{\left[\mathrm{O}_{2}\right]_{\text {bulk }}}{\delta_{\text {diff }}}$

Under one atm of $\mathrm{O}_{2}$, we can estimate a flux of $\phi_{\mathrm{O}_{2}}=0.9 \mathrm{nmol} \cdot \mathrm{cm}^{-}$ ${ }^{2} \cdot \mathrm{s}^{-1}$ if considering $\delta_{\text {diff }}=300 \mu \mathrm{m}$ and $\left[\mathrm{O}_{2}\right]_{\text {bulk }}=1.4 \mathrm{mM}$. This value can be compared to the electron flux of $3.1 \mathrm{nmol} \cdot \mathrm{cm}^{-2} \cdot \mathrm{s}^{-1}$ that can be extracted from the current densities at the end of reduction steps performed at $E_{\text {cat }}=-0.8 \mathrm{~V}$ and $-0.85 \mathrm{~V}$ (Figure S6). The corresponding ratio of 3.4 , close to 4 , is most likely indicative of $\mathrm{O}_{2}$ being predominantly reduced into $\mathrm{H}_{2} \mathrm{O}$ through a 4 electron process, which agrees with recent literature reports for other $\mathrm{Mn}(\mathrm{III})$ porphyrin catalysts. ${ }^{[47,48]}$ At $-0.8 \mathrm{~V}$, the current density is decreased by a factor of 4.7 upon switching from a pure $\mathrm{O}_{2}$ atmosphere to air $\left(\sim 20 \% \mathrm{O}_{2}\right)$, which is fully consistent with the $\left[\mathrm{O}_{2}\right]_{\text {bulk }}$ ratio between the two solutions.

The chronoabsorptograms (CAs) simultaneously monitored at 432 and $780 \mathrm{~nm}$ under argon, air or pure $\mathrm{O}_{2}$ atmosphere are reported in Figure 3 and $\mathrm{S} 6$. In all $\mathrm{CA}_{432}$, we observe a fast exponential accumulation of the reduced catalyst upon applying $E_{\text {cat }}=-0.8 \mathrm{~V}$, until the absorbance asymptotically reaches a stable value. At the end of the $15 \mathrm{~s}$ reduction step, back accumulation of the oxidized catalyst is observed in all experiments, as indicated by the 432-nm absorbance decrease down to zero. Under OCP, this only occurs after a significant lag time during which $A_{432}$ remains almost constant (a slight decrease is observed at 

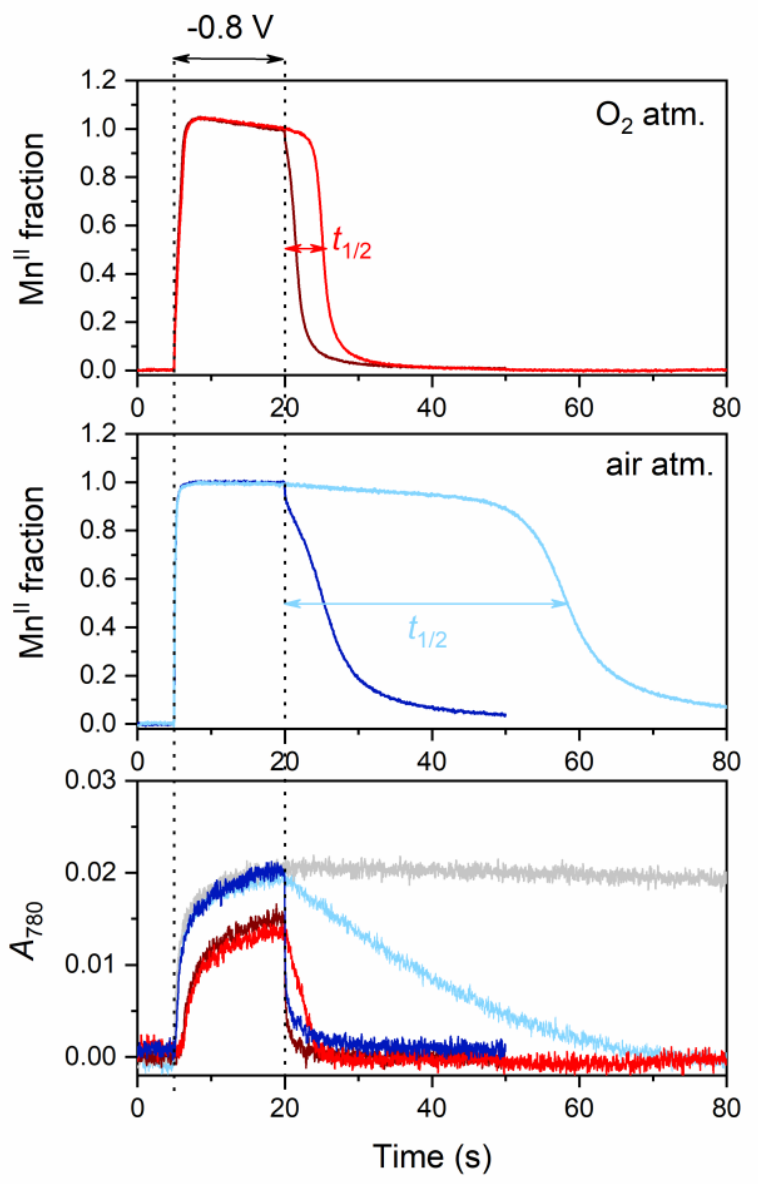

Figure 3. UV-Vis chronoabsorptograms monitored at (top and middle) 432 and (bottom) $780 \mathrm{~nm}$ during the time course of a potential step experiment applied at a Mn-P/GLAD- $-\mathrm{TiO}_{2}$ electrode. A cathodic potential of $E_{\mathrm{cat}}=-0.8 \mathrm{~V}$ (vs. $\mathrm{Ag} / \mathrm{AgCl}$ ) was first applied during $15 \mathrm{~s}$ under (light grey) argon, (blue and light blue) air, or (wine and red) $\mathrm{O}_{2}$ atmosphere. At the end of this $15 \mathrm{~s}$ reduction step, the applied potential was either (wine and blue) stepped to an anodic value of $E_{\mathrm{an}}=0 \mathrm{~V}$ or (light grey, red and light blue) left to the open circuit potential value. In the $\mathrm{CVA}_{432}$, the $\mathrm{Mn}^{\text {II-P }}$ surface coverage was normalized to $\Gamma^{0}$. The experiments were conducted at $25^{\circ} \mathrm{C}$ in a $0.1 \mathrm{M} \mathrm{HEPES}$ buffer $+0.05 \mathrm{M} \mathrm{Na}_{2} \mathrm{SO}_{4}$ at $\mathrm{pH} 7.0$.

electrodes with high catalyst loading and attributed to slow catalyst desorption). In order to quantify this lag time, we defined $t_{1 / 2}$ as the time required to recover $50 \%$ of the oxidized catalyst (Figure 3). The $t_{1 / 2}$ values are reported in Table S1, together with the details on the experimental conditions such as the catalyst surface concentration, the $\left[\mathrm{O}_{2}\right]_{\text {bulk }}$ value, and the applied potential conditions (i.e., $E_{\mathrm{an}}=0 \mathrm{~V}$ or OCP). The data show that $t_{1 / 2}$ is almost unaffected by the catalyst surface concentration, but it is systematically higher under air than $\mathrm{O}_{2}$ atmosphere, which is consistent with the lower incoming flux of $\mathrm{O}_{2}$ in air than in $\mathrm{O}_{2}$ atmosphere (eq. 6). Furthermore, $t_{1 / 2}$ is also higher under OCP than upon applying an anodic potential of $0 \mathrm{~V}$, and this effect is all the more marked as the potential applied during the reduction step is more negative. These last observations are rather counterintuitive given that we assume steady-state conditions are reached at the end of the reduction step (which must therefore continue to apply at the beginning of the following step). Accordingly, the reoxidation rate of $\mathrm{Mn}^{\mathrm{II}}-\mathrm{P}$ (and thus $t_{1 / 2}$ ) is expected to depend only on the incoming $\mathrm{O}_{2}$ flux, but this is clearly not what we observe.
During the reduction step performed under $\mathrm{O}_{2}$, one can notice that the absorbance increase at $780 \mathrm{~nm}$ is not only slightly delayed but also decreased in terms of amplitude compared to that under argon (Figure 3). The delay suggests that electron accumulation in $\mathrm{TiO}_{2}$ can start only when $\mathrm{O}_{2}$ at the electrode interface is significantly depleted. Besides, the smaller amplitude supports the hypothesis that a steady-state regime is reached, with a constant incoming flux of $\mathrm{O}_{2}$ consuming a fraction of the electrons stored in $\mathrm{TiO}_{2}$. These effects are significantly less pronounced under air, which is consistent with the fact that $\left[\mathrm{O}_{2}\right]_{\text {bulk }}$ is significantly lower.

Overall, these observations are in line with those made above in the cyclic voltabsorptometric experiments, confirming that charge storage at the $\mathrm{TiO}_{2}$ film is significantly affected by the competitive catalysis. At the end of the reductive potential step, the amount of electrons stored in $\mathrm{TiO}_{2}$ under $\mathrm{O}_{2}$ was estimated to be 15 or 25 $\mathrm{nmol} \cdot \mathrm{cm}^{-2}$ for $E_{\text {cat }}=-0.8 \mathrm{~V}$ and $-0.85 \mathrm{~V}$, respectively (which is equivalent to 270 and $450 \mathrm{mM}$ of electrons stored in the $0.55 \mu \mathrm{m}$ thick film, see Scheme 2). The large difference between these two values is attributed to the proton insertion-coupled electron storage described by reaction 1 , which becomes more efficient as the applied potential is downshifted toward the $E^{\circ}{ }_{\text {TiогттіоО }}$ value. If the electrode is next left to the OCP, the $780 \mathrm{~nm}$ absorbance remains stable under argon but decreases, almost linearly with time, to zero in the presence of $\mathrm{O}_{2}$. This signals the complete consumption of electrons accumulated in $\mathrm{TiO}_{2}$ by $\mathrm{O}_{2}$, a process which occurs catalytically through the $\mathbf{M n}-\mathbf{P}$ catalyst, as we demonstrated above, neglecting direct $\mathrm{O}_{2}$ reduction at the reduced metal oxide. The linear decrease of $A_{780}$ over time indicates a constant consumption rate of the electrons stored in $\mathrm{TiO}_{2}$, which was estimated to be $3 \mathrm{nmol} \cdot \mathrm{cm}^{-2} \cdot \mathrm{s}^{-1}$ from the slope of the $A_{780}$ decrease monitored under $\mathrm{O}_{2}$. We found this value to be independent of the reduction potential applied during the previous reductive step and thus of the amount of electrons stored in the $\mathrm{TiO}_{2}$ film. Its value is however decreased to $0.57 \mathrm{nmol} \cdot \mathrm{cm}^{-}$ ${ }^{2} \cdot \mathrm{s}^{-1}$ under air (i.e., 5.3 times less than under $\mathrm{O}_{2}$ ) and thus proportional to the $\left[\mathrm{O}_{2}\right]_{\text {bulk }}$ concentration and the incoming $\mathrm{O}_{2}$ flux. We further notice that these rate values are close to the electron flux values achieved at the end of the reductive step (see above) and associated to steady-state conditions. Therefore, it seems that the steady-state regime extends beyond the application of a reducing potential in the present experiment. We can thus conclude that the partially reduced $\mathrm{TiO}_{2}$ film acts as an electron storage reservoir (like in a battery), which can be delivered to the immobilized catalyst in the absence of any applied potential. Under OCP, the time required to empty this reservoir is proportional to the amount of electrons initially stored, and we notice that its value is close to the $t_{1 / 2}$ value characterizing back accumulation of $\mathrm{Mn}^{\mathrm{III}}-\mathrm{P}$ (Table S1). Accordingly, back accumulation of the oxidized catalyst only occurs once the reservoir is almost fully depleted. This is strongly dependent on the applied potential as demonstrated when an anodic value of 0 $\mathrm{V}$ is applied. Under this latter condition, the $\mathrm{TiO}_{2}$ film is very quickly discharged as attested by the instantaneous decrease of $A_{780}$ to zero observed upon switching the applied potential from $E_{\text {cat }}$ to $E_{\text {an }}$. Accordingly, re-accumulation of the oxidized catalyst is observed without significant lag time (Figure 3).

Overall, these observations are strongly reminiscent of what we observed by comparing the $\mathrm{CVA}_{432}$ and $\mathrm{CVA}_{780}$ monitored during the CV experiments. We are thus convinced that the charge 
accumulated in $\mathrm{TiO}_{2}$ once the electrode is significantly substratedepleted plays a significant role in the hysteresis of the $\mathrm{CVA}_{432}$ and DCVA ${ }_{432}$, notably by delaying the back accumulation of $\mathrm{Mn}^{\text {III- }}$ $P$ during the reverse scan. Since this process is strongly dependent on the applied potential, which regulates the amount of charge stored in $\mathrm{TiO}_{2}$, its contribution is easier to analyze from CVA experiments carried out at fixed potential values, than from CV experiments, which involve a continuous change of the applied potential.

\section{Conclusion}

The present study provides significant new insights into the electrochemical reactivity of a semiconductive nanostructured metal oxide film modified by an immobilized molecular catalyst, as commonly used in photoelectrochemical devices. For the first time, we provide evidence for a significant interplay between catalysis and charge storage at the metal-oxide matrix. This study was made possible thanks to UV-Vis spectroelectrochemistry which allows us to deconvolute the intrinsic reactivity of the semiconductor film from that of the immobilized catalyst. We notably demonstrate $(I)$ that electron accumulation in $\mathrm{TiO}_{2}$ is delayed in the presence of the substrate until mass-transport becomes rate-limiting, and (ii) that the large amount of charge stored within the material (once significantly depleted in $\mathrm{O}_{2}$ ) acts as an "electron storage unit" allowing catalysis to continue until full electron depletion is achieved. Since charge accumulation is a common feature of many metal oxide films, we anticipate that this specific reactivity has a generic character beyond $\mathrm{TiO}_{2}$ as well as $\mathrm{O}_{2}$ reduction.

\section{Experimental Section}

Materials. All chemicals were obtained commercially from Acros or SigmaAldrich and used without further purification. Analytical thin-layer chromatography (TLC) was carried out using Merck silica gel 60 F-254 plates (precoated sheets, $0.2 \mathrm{~mm}$ thick, with fluorescence indicator F254) and Merck DC Kieselgel 60 F-254 aluminum sheets. The spots were directly visualized or through illumination with UV lamp $(\lambda=254 / 365 \mathrm{~nm})$. Column chromatography purification was carried out on neutral alumina (Aluminium oxide 90, 63-200 $\mu \mathrm{m}$, Merck). Size exclusion chromatography was performed using Bio-Beads $\mathrm{S}-\mathrm{X} 3$ Resin (Bio-Rad). 10 (Diethoxyphosphoryl)-5,15-diphenylporphyrin (2H-P-Et) was prepared according to literature procedure. ${ }^{[55]}$ All aqueous solutions were made with deionized water $(18.2 \mathrm{M} \Omega \cdot \mathrm{cm})$ from a TKA MicroPure UV purification system.

Instrumentation. UV-Vis spectra were obtained on a Jasco V-550 spectrophotometer by using a rectangular quartz cell (Hellma, 100-QS, 45 $\times 12.5 \times 12.5 \mathrm{~mm}$, pathlength: $10 \mathrm{~mm}$, chamber volume: $3.5 \mathrm{~mL})$. IR spectra were recorded with FT/IR-4200 Jasco spectrometer using a Jasco ATR PRO470-H accessory. Accurate mass measurements (HRMS) were made on a hybrid quadrupole-time-of-flight mass spectrometer Bruker micrOTOF-QII at the "Center de Spectrométrie de Masse", University of Lyon. Solutions in $\mathrm{CHCl}_{3} /$ methanol $(1: 1, \mathrm{v} / \mathrm{v})$ were used for the analyses. The analyses were performed in positive mode using full scan MS with a mass range from 50 to $2000 \mathrm{Da}$ at an acquisition rate of $1 \mathrm{~Hz}$.

Synthesis. [10-(Diethoxyphosphoryl)-5,15-diphenylporphyrinato]manganese(II) acetate (Mn-P-Et). A $10 \mathrm{~mL}$ two-neck flask equipped with a magnetic stirrer and a reflux condenser with drying tube was charged with $50 \mathrm{mg}$ (0.084 mmol) of $\mathbf{2 H}-\mathbf{P}-\mathbf{E t}, 21 \mathrm{mg}$ of anhydrous manganese(II) chloride $(0.167 \mathrm{mmol})$, glacial acetic acid $(6 \mathrm{~mL})$ and acetic anhydride $(0.25 \mathrm{~mL})$. The reaction mixture was refluxed for $4 \mathrm{~h}$. After complete conversion of the free base porphyrin (TLC monitoring), the reaction mixture was cooled to room temperature and evaporated under reduced pressure. The solid residue was taken up in dichloromethane and purified by column chromatography on alumina using a gradient elution with $\mathrm{CH}_{2} \mathrm{Cl}_{2} / \mathrm{MeOH}$ mixture (from 100:0 to $98.5: 1.5$, v/v). Dark green-brown fraction was evaporated under reduced pressure and dissolved in chloroform. This solution was purified by size exclusion chromatography using chloroform as an eluent. Porphyrin Mn-P-Et was obtained as a dark swamp powder, yield $43 \mathrm{mg}$ (72\%). FT-IR (neat): $v=2916(\mathrm{~m}), 2849(\mathrm{~m})$, 1720 (m, COO), 1598 (w), 1576 (w), $1554(w), 1527(w), 1527(w), 1473$ $(\mathrm{m}, \mathrm{COO}), 1440(\mathrm{~m}), 1380(\mathrm{w}), 1366(\mathrm{w}), 1355(\mathrm{w}), 1319(\mathrm{w}), 1287(\mathrm{w})$, $1254(\mathrm{~m}), 1231(\mathrm{~m}), 1205(\mathrm{~m}, \mathrm{P}=\mathrm{O}), 1157$ (m, P=O), $1091(\mathrm{w}), 1067(\mathrm{~m})$, 1040 (m), 1006 (s, P-O), 959 (s, P-O), 938 (s), 891 (s), 872 (s), 793 (s),

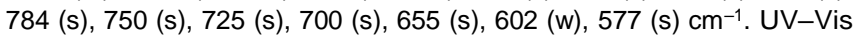
$\left(\mathrm{CHCl}_{3}\right): \lambda_{\max }\left(\varepsilon, \mathrm{M}^{-1} \cdot \mathrm{cm}^{-1}\right)=605$ (4860), 571 (9098), 475 (87201), 398 (27414), 369 (48640), 348 (39931), 275 (15216) nm. HRMS (ESI): $\mathrm{m} / z$ calcd. for $\mathrm{C}_{36} \mathrm{H}_{29} \mathrm{MnN}_{4} \mathrm{O}_{3} \mathrm{P}\left[\mathrm{M}-\mathrm{OAc}^{-}\right]^{+}$651.1358, found 651.1352.

Bis(tetraethylammonium) [(acetato)manganese(III)(10,20-diphenylporphyrin-5-yl)]phosphonate (Mn-P). Porphyrin Mn-P-Et (43 mg, 0.061 $\mathrm{mmol}$ ) was placed in a Schlenk tube and the evacuation/Ar refill cycle was repeated three times. Anhydrous dichloromethane $(6 \mathrm{~mL})$, triethylamine $(0.25 \mathrm{~mL}, 1.80 \mathrm{mmol})$ and $\operatorname{TMSBr}(0.5 \mathrm{~mL}, 3.79 \mathrm{mmol})$ were added by syringe and the reaction mixture was stirred for $48 \mathrm{~h}$ at room temperature. The volatiles were distilled under reduced pressure (2 Torr) and the reaction vessel was refilled with Ar. Methanol $(1 \mathrm{~mL})$ was added by syringe and the reaction mixture was stirred for $5 \mathrm{~min}$ at room temperature. Evaporation of volatiles afforded porphyrinylphosphonic acid $\mathbf{M n - P}$ in quantitative yield as a mixture with tetraethylammonium bromide. This crude solid was kept in the congelator at $-18^{\circ} \mathrm{C}$ and used for the electrode preparation. The solid was purified by size exclusion chromatography using $\mathrm{CHCl}_{3} / \mathrm{MeOH}(1: 1, \mathrm{v} / \mathrm{v})$ as an eluent to prepare pure $\mathbf{M n}-\mathbf{P}$ as a dark swamp solid. FT-IR (neat): v= 3351 (br m, OH), 2922 (s), 2852 (s), 1741 (m, COO), 1600 (m), 1455 (m, COO), $1440(\mathrm{~m}), 1377$ (m), 1257 (w, P=O), 1221 (w, P=O), 1065 (s, P-O), 1012 (s, P-O), 980 (s, P-O), 790 (s), 775 (s), $763(\mathrm{~s}), 729(\mathrm{~s}), 720(\mathrm{~s}), 701(\mathrm{~s}), 655(\mathrm{~m}), 636(\mathrm{w}), 620(\mathrm{~m}), 602(\mathrm{~s})$ 593 (s), 585 (s), 576 (s), 568 (s). UV-Vis $\left(\mathrm{CHCl}_{3} /\right.$ methanol): $\lambda_{\max }\left(\varepsilon, \mathrm{M}^{-}\right.$ $\left.{ }^{1} \cdot \mathrm{cm}^{-1}\right)=775$ (684), 685 (699), 562 (6013), 465 (47425), 397 (23321), 376 (25616), 320 (13828) nm. HRMS (ESI): m/z calcd. for $\mathrm{C}_{32} \mathrm{H}_{21} \mathrm{MnN}_{4} \mathrm{O}_{3} \mathrm{P}$ [M - $\left.\mathrm{OAc}^{-}-2\left(\mathrm{NEt}_{4}\right)^{+}+2 \mathrm{H}^{+}\right]^{+}$595.0726, found 595.0726; calcd. for $\mathrm{C}_{32} \mathrm{H}_{21} \mathrm{MnN}_{4} \mathrm{O}_{3} \mathrm{P}\left[\mathrm{M}-\mathrm{OAc}^{-}-2\left(\mathrm{NEt}_{4}\right)^{+}+\mathrm{H}^{+}+\mathrm{Na}^{+}\right]^{+} 617.0546$, found 617.0544.

Glancing angle deposition. ITO and $\mathrm{TiO}_{2}$ electrodes were each formed using glancing angle deposition, with the nanostructured thin film added to commercially-supplied glass substrates with electrically-conducting ITO coatings (8-12 $\Omega$ /sq., Delta Technologies). ${ }^{[41]}$ The glass/ITO substrates were cleaned prior to GLAD by successive sonication in dichloromethane, water and isopropanol, and the deposition process was performed under high vacuum $\left(<1 \times 10^{-4}\right.$ Torr). For GLAD-ITO, the cleaned substrates were affixed to a mounting plate inclined at an $80^{\circ}$ angle with respect to the incoming ITO vapor flux, and the substrates were rotated during deposition at a rate of one complete rotation for every $10 \mathrm{~nm}$ of film growth. The final thickness was $500 \mathrm{~nm}$. For GLAD- $\mathrm{TiO}_{2}$, the substrates were maintained at an angle of $72^{\circ}$ with respect to the incoming $\mathrm{TiO}_{2}$ vapor flux, and they were rotated at a rate of one rotation for every $10 \mathrm{~nm}$ of film growth. The final thickness was $550 \mathrm{~nm}$.

Electrode cleaning and functionalization. Chemical cleaning of the GLAD-ITO electrodes was performed according to the procedure previously established. ${ }^{[56]}$ Electrodes were successively soaked during 30 $\min$ at $50^{\circ} \mathrm{C}$ in trichloroethylene, acetone and ethanol. Cleaning of the GLAD- $\mathrm{TiO}_{2}$ electrodes was performed by $15 \mathrm{~min}$ exposure under UVozone (UV/O $/ \mathrm{O}_{3}$ procleaner plus, Bioforce nanosciences), followed by consequent $15 \mathrm{~min}$ immersion in ethanol and acetone. After cleaning, electrodes were left to dry in air and an electroactive surface of ca. $0.5 \mathrm{~cm}^{2}$ 
was delimited with an insulating nail varnish. Further modification of the electrodes by the porphyrin catalyst was achieved according to the procedure we previously established.[57] The GLAD electrodes were soaked overnight at $4^{\circ} \mathrm{C}$ in a $\sim 25 \mu \mathrm{M} \mathrm{Mn}-\mathrm{P}$ solution (1:9 mixture of DMSO and water) adjusted to $\mathrm{pH} 4-5$ with $\mathrm{HCl}$. Thereafter, the functionalized GLAD electrodes were rinsed with Milli-Q water and immersed in an aqueous buffer solution (i.e., a 0.1 M HEPES buffer with $0.05 \mathrm{M} \mathrm{Na}_{2} \mathrm{SO}_{4}$, $\mathrm{pH}$ 7.0) for at least 20 min prior use to desorb to poorly physisorbed fraction of the catalyst.

Real-time UV-Vis absorption spectroelectrochemistry. The spectroelectrochemical experiments (cyclic voltabsorptometry and chronoabsorptometry) were performed in a one-compartment spectroelectrochemical cell using and Autolab PGSTAT-12 potentiostat controlled by the GPES-4 software and synchronized to a TORUS UVvisible spectrometer (Ocean Optics) equipped with optical fibers and a balanced deuterium tungsten source (Micropack). The GLAD electrodes were positioned perpendicular to the $1 \mathrm{~cm}$ optical path of the quartz cell for measurements in transmission mode. The cell was filled with $1.2 \mathrm{~mL}$ of the buffer solution (0.1 M HEPES + $0.05 \mathrm{M} \mathrm{Na}_{2} \mathrm{SO}_{4}, \mathrm{pH} 7.0$ ) and thermostated at $25^{\circ} \mathrm{C}$. A constant flow of argon, air or $\mathrm{O}_{2}$ was maintained during the entire experiment. For electrocatalytic experiments, air or $\mathrm{O}_{2}$ was also bubbled into the electrolyte solution in between two measurements to ensure recovering a homogeneous dioxygen concentration. An Ag/AgCl/ $/ \mathrm{KCl}_{\text {sat }}$ electrode (WPI, Dri-Ref, + $0.2 \mathrm{~V}$ vs NHE at $25^{\circ} \mathrm{C}$ ) was used as the reference electrode and a Pt wire was used as the counter electrode. Integration time was fixed to $3 \mathrm{~ms}$ and the number of average scans was adjusted to the time scale of the electrochemical experiments. Satisfactory signal-to-noise ratio was achieved by averaging 6 scans at $0.1 \mathrm{~V} \cdot \mathrm{s}^{-1}$. Experimental derivative cyclic voltabsorptograms (DCVAs) were calculated using the Origin software and smoothed using a second-order Savistky-Golay algorithm. The surface coverage of the immobilized $\mathbf{M n}-\mathbf{P}$ was estimated from integration of the faradaic current recorded at GLAD-ITO electrodes, which in turns allowed determination of the $\Delta \varepsilon 432$ value $\left(380000 \mathrm{M}^{-1} \cdot \mathrm{cm}^{-1}\right)$ from the total absorbance variation in the $\mathrm{CVA}_{432}$.

\section{Acknowledgements}

The authors thank J. Michalak for his technical support during the porphyrin synthesis.

[1] X. Chen, S. S. Mao, Chem. Rev. 2007, 107, 2891-2959.

[2] T. Berger, D. Monllor-Satoca, M. Jankulovska, T. Lana-Villarreal, R. Gomez, ChemPhysChem 2012, 13, 2824-2875.

[3] W. Li, Z. Wu, J. Wang, A. A. Elzatahry, D. Zhao, Chem. Mater 2014, 26, 287-298.

[4] a Fujishima, K. Honda, Nature 1972, 238, 37-38.

[5] G. N. Schrauzer, T. D. Guth, J. Am. Chem. Soc. 1977, 99, 71897193.

[6] T. Inoue, A. Fujishima, S. Konishi, K. Honda, Nature 1979, 277 , 637-638.

[7] Y. Ma, X. L. Wang, Y. S. Jia, X. B. Chen, H. X. Han, C. Li, Chem. Rev. 2014, 114, 9987-10043.

[8] J. Schneider, M. Matsuoka, M. Takeuchi, J. Zhang, Y. Horiuchi, M. Anpo, D. W. Bahnemann, Chem. Rev. 2014, 114, 9919-9986.

[9] W. Chen, G. Li, A. Pei, Y. Li, L. Liao, H. Wang, J. Wan, Z. Liang, G. Chen, H. Zhang, et al., Nat. Energy 2018, 3, 428-435.

[10] X. Li, J. Yu, M. Jaroniec, X. Chen, Chem. Rev. 2019, 119, 39624179.

[11] A. Meng, L. Zhang, B. Cheng, J. Yu, Adv. Mater. 2019, 1807660.
J. L. White, M. F. Baruch, J. E. Pander, Y. Hu, I. C. Fortmeyer, J. E. Park, T. Zhang, K. Liao, J. Gu, Y. Yan, et al., Chem. Rev. 2015, 115, 12888-12935.

[13] K. E. Dalle, J. Warnan, J. J. Leung, B. Reuillard, I. S. Karmel, E. Reisner, Chem. Rev. 2019, 119, 2752-2875.

[14] K. J. Lee, N. Elgrishi, B. Kandemir, J. L. Dempsey, Nat. Rev. Chem. 2017, 1, 0039 .

[15] C. W. Machan, Curr. Opin. Electrochem. 2019, 15, 42-49.

[16] M. Schreier, J. Luo, P. Gao, T. Moehl, M. T. Mayer, M. Grätzel, J. Am. Chem. Soc. 2016, 138, 1938-1946.

[17] T. E. Rosser, C. D. Windle, E. Reisner, Angew. Chemie - Int. Ed. 2016, 55, 7388-7392.

[18] T. E. Rosser, M. A. Gross, Y. H. Lai, E. Reisner, Chem. Sci. 2016 7, 4024-4035.

[19] J. J. Leung, J. Warnan, D. H. Nam, J. Z. Zhang, J. Willkomm, E. Reisner, Chem. Sci. 2017, 8, 5172-5180.

[20] S. Chandrasekaran, N. Kaeffer, L. Cagnon, D. Aldakov, J. Fize, G Nonglaton, F. Baleras, P. Mailley, V. Artero, Chem. Sci. 2019, 10, 4469-4475.

[21] T. E. Rosser, E. Reisner, ACS Catal. 2017, 7, 3131-3141.

[22] C. Renault, C. P. C. P. Andrieux, R. T. R. T. Tucker, M. J. M. J. Brett, V. Balland, B. Limoges, J. Am. Chem. Soc. 2012, 134, 683445.

[23] C. Renault, L. Nicole, C. Sanchez, C. Costentin, V. Balland, B. Limoges, Phys. Chem. Chem. Phys. 2015, 17, 10592-10607.

[24] C. Renault, V. Balland, B. Limoges, C. Costentin, J. Phys. Chem. C 2015, 119, 14929-14937.

[25] G. Rothenberger, D. Fitzmaurice, M. Graetzel, J. Phys. Chem. 1992, 96, 5983-5986.

[26] G. Boschloo, D. Fitzmaurice, J. Phys. Chem. B 1999, 103, 78607868.

[27] L. Bertoluzzi, L. Badia-Bou, F. Fabregat-Santiago, S. Gimenez, J. Bisquert, J. Phys. Chem. Lett. 2013, 4, 1334-1339.

[28] B. O'Regan, M. Grätzel, D. Fitzmaurice, Chem. Phys. Lett. 1991, 183, 89-93.

[29] F. Cao, G. Oskam, P. C. Searson, J. M. Stipkala, T. A. Heimer, F. Farzad, G. J. Meyer, J. Phys. Chem. 1995, 99, 11974-11980.

[30] G. Boschloo, D. Fitzmaurice, J. Phys. Chem. B 1999, 103, 22282231.

[31] D. Mandal, T. W. Hamann, Phys. Chem. Chem. Phys. 2015, 17, 11156-11160.

[32] T. Berger, J. A. Anta, V. Morales-Florez, J. Phys. Chem. C 2012, 116, 11444-11455.

[33] L. A. Lyon, J. T. Hupp, J. Phys. Chem. B 1999, 103, 4623-4628.

[34] B. I. Lemon, J. T. Hupp, J. Phys. Chem. 1996, 100, 14578-14580.

[35] Y. Yan, W. Shi, W. Peng, Y. Lin, C. Zhang, L. Li, Y. Sun, H. Ju, J. Zhu, W. Ma, et al., Commun. Chem. 2019, 2, 88.

[36] J. N. Schrauben, R. Hayoun, C. N. Valdez, M. Braten, L. Fridley, J. M. Mayer, Science 2012, 336, 1298-1301.

[37] J. Castillo-lora, M. F. Delley, S. M. Laga, J. M. Mayer, J. Phys. Chem. Lett. 2020, 11, 7687-7691.

[38] Y.-S. Kim, S. Kriegel, K. D. Harris, C. Costentin, B. Limoges, V. Balland, J. Phys. Chem. C 2017, 121, 10325-10335.

[39] Y.-S. Kim, K. D. Harris, B. Limoges, V. Balland, Chem. Sci. 2019, 10, 8752-8763.

[40] N. Makivic, J.-Y. Cho, K. D. . Harris, J.-M. Tarascon, B. Limoges, V. Balland, submitted 2021, DOI 10.26434/chemrxiv.14254298.v1. 
[41] K. M. Krause, M. T. Taschuk, K. D. Harris, D. A. Rider, N. G. Wakefield, J. C. Sit, J. M. Buriak, M. Thommes, M. J. Brett, Langmuir 2010, 26, 4368-76.

[42] C. Queffélec, M. Petit, P. Janvier, D. A. Knight, B. Bujoli, Chem. Rev. 2012, 112, 3777-3807.

[43] G. Guerrero, J. G. Alauzun, M. Granier, D. Laurencin, P. H. Mutin, Dalton Trans. 2013, 42, 12569-85.

[44] M. Wagstaffe, A. G. Thomas, M. J. Jackman, M. Torres-Molina, K. L. Syres, K. Handrup, J. Phys. Chem. C 2016, 120, 1693-1700.

[45] O. Ikeda, T. Kojima, H. Tamura, J. Electroanal. Chem. 1986, 200, 323-332.

[46] S. E. Creager, R. W. Murray, Inorg. Chem. 1987, 26, 2612-2618.

[47] G. Passard, D. K. Dogutan, M. Qiu, C. Costentin, D. G. Nocera, ACS Catal. 2018, 8, 8671-8679.

[48] L. E. Lieske, S. L. Hooe, A. W. Nichols, C. W. Machan, Dalton Trans. 2019, 48, 8633-8641.

[49] A. Harriman, G. Porter, J. Chem. Soc. Faraday Trans. 2 1979, 75, 1532-1542.

[50] F. Fabregat-Santiago, I. Mora-Seró, G. Garcia-Belmonte, J. Bisquert, J. Phys. Chem. B 2003, 107, 758-768.

[51] L. J. Boucher, Coord. Chem. Rev. 1972, 7, 289-329.

[52] C. Renault, V. Balland, E. Martinez-Ferrero, L. Nicole, C. Sanchez, B. Limoges, Chem. Commun. 2009, 7494-7496.

[53] D. R. Lide, Ed. , CRC Hanbook of Chemistry and Physics, CRC Press, Bocan Raton, FL, 2005.

[54] C. Amatore, S. Szunerits, L. Thouin, J. S. Warkocz, J. Electroanal. Chem. 2001, 500, 62-70.

[55] Y. Y. Enakieva, J. Michalak, I. A. Abdulaeva, M. V. Volostnykh, C. Stern, R. Guilard, A. G. Bessmertnykh-Lemeune, Y. G. Gorbunova, A. Y. Tsivadze, K. M. Kadish, European J. Org. Chem. 2016, 2016, 4881-4892.

[56] A. Forget, R. T. Tucker, M. J. Brett, B. Limoges, V. Balland, Chem. Commun. 2015, 51, 6944-6947.

[57] A. Forget, B. Limoges, V. Balland, Langmuir 2015, 31, 1931-1940. 


\section{Interplay between charge accumulation and oxygen reduction catalysis in nanostructured $\mathrm{TiO}_{2}$ electrodes functionalized with a molecular catalyst}

Yee-Seul Kim, ${ }^{[a]}$ Sébastien Kriegel, ${ }^{[a]}$ Alla Bessmertnykh-Lemeune, ${ }^{[b]}$ Kenneth D. Harris, ${ }^{[c]}$

Benoît Limoges, ${ }^{*[a]}$ and Véronique Balland ${ }^{*[a]}$

[a] Dr. Y-S Kim, Dr. S. Kriegel, Dr. B. Limoges and Dr. V. Balland

Université de Paris, Laboratoire d'Electrochimie Moléculaire, UMR 7591, CNRS, F-75013 Paris, France

E-mail: limoges@u-paris.fr, veronique.balland@u-paris.fr

[b] Dr. A. Bessmertnykh-Lemeune

ENS de Lyon, UMR 5182, CNRS, Université Claude Bernard Lyon 1, Laboratoire de Chimie, 69342 Lyon, France

[c] Dr. K.D. Harris

NRC Nanotechnology Research Centre, Edmonton, Alberta T6G 2M9, Canada

\& Department of Mechanical Engineering, University of Alberta, Edmonton, Alberta T6G 2V4, Canada 

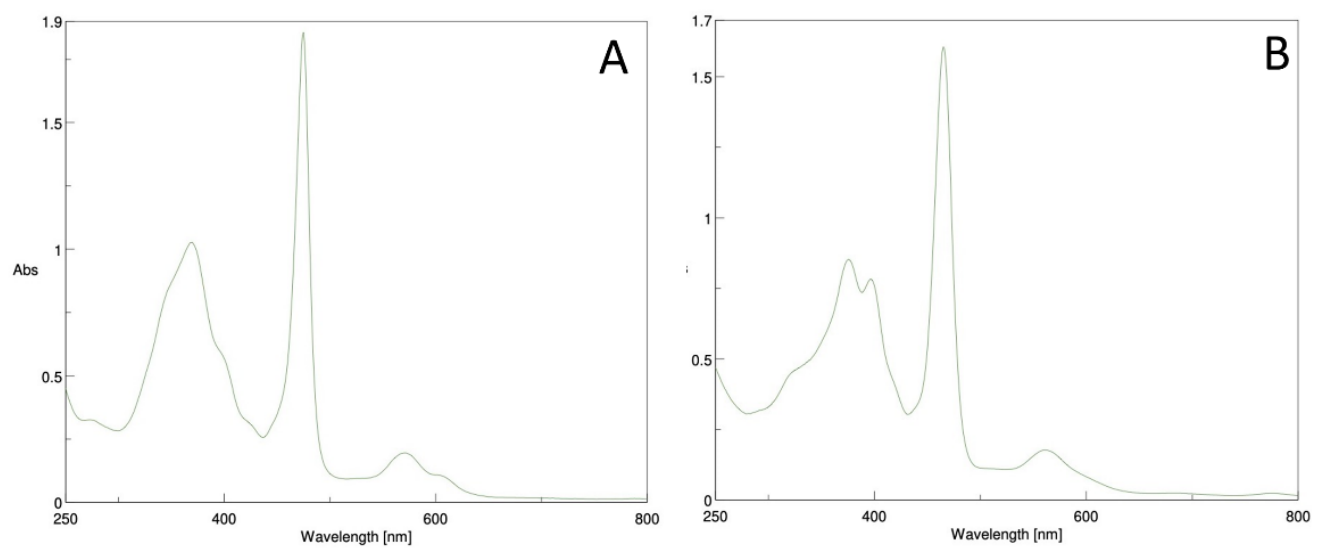

Figure S1. UV-Vis spectrum of (A) Mn-P-Et at a concentration of $0.021 \mathrm{mM}$ in $\mathrm{CHCl}_{3}$ and (B) $\mathrm{Mn}-\mathrm{P}$ at a concentration of $0.034 \mathrm{mM}$ in $\mathrm{CHCl}_{3} / \mathrm{MeOH}(1: 1, \mathrm{v} / \mathrm{v})$ mixture.

Comment: Both complexes display UV-Vis spectra characteristic of manganese(III) porphyrins showing specific shapes compared to other porphyrin complexes due to strong metal-porphyrin $\pi$ interactions. ${ }^{1}$ The mixing of metal and porphyrin orbitals leads to appearance of a number of charge-transfer bands which alter classical electron absorption spectra of the porphyrin complexes in which only $\pi-\pi^{*}$ transitions of the macrocycle are observed. For example, in the spectrum of $\mathrm{Mn}$-P-Et in $\mathrm{CHCl}_{3}$, several bands appear in the region of 300-450 nm as a broad band with the maximum at $369 \mathrm{~nm}(\log \varepsilon=4.68$, $\mathrm{VI}$ band) and a sharp charge-transfer band is observed at $475 \mathrm{~nm}(\log \varepsilon=4.94, \mathrm{~V}$ band). Moreover, less intensive bands appear at $571 \mathrm{~nm}$ ( $\log \varepsilon=3.96$, IV band) and 605 ( $\log \varepsilon=3.68$, III band). 

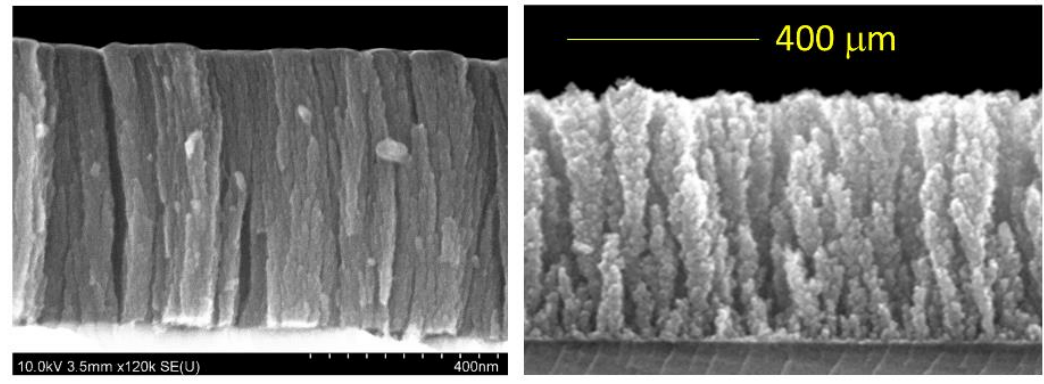

Figure S2. Cross-sectional scanning electron microscopy (SEM) images obtained the (Left) GLAD-TiO 2 and (right) GLAD-ITO electrodes. 

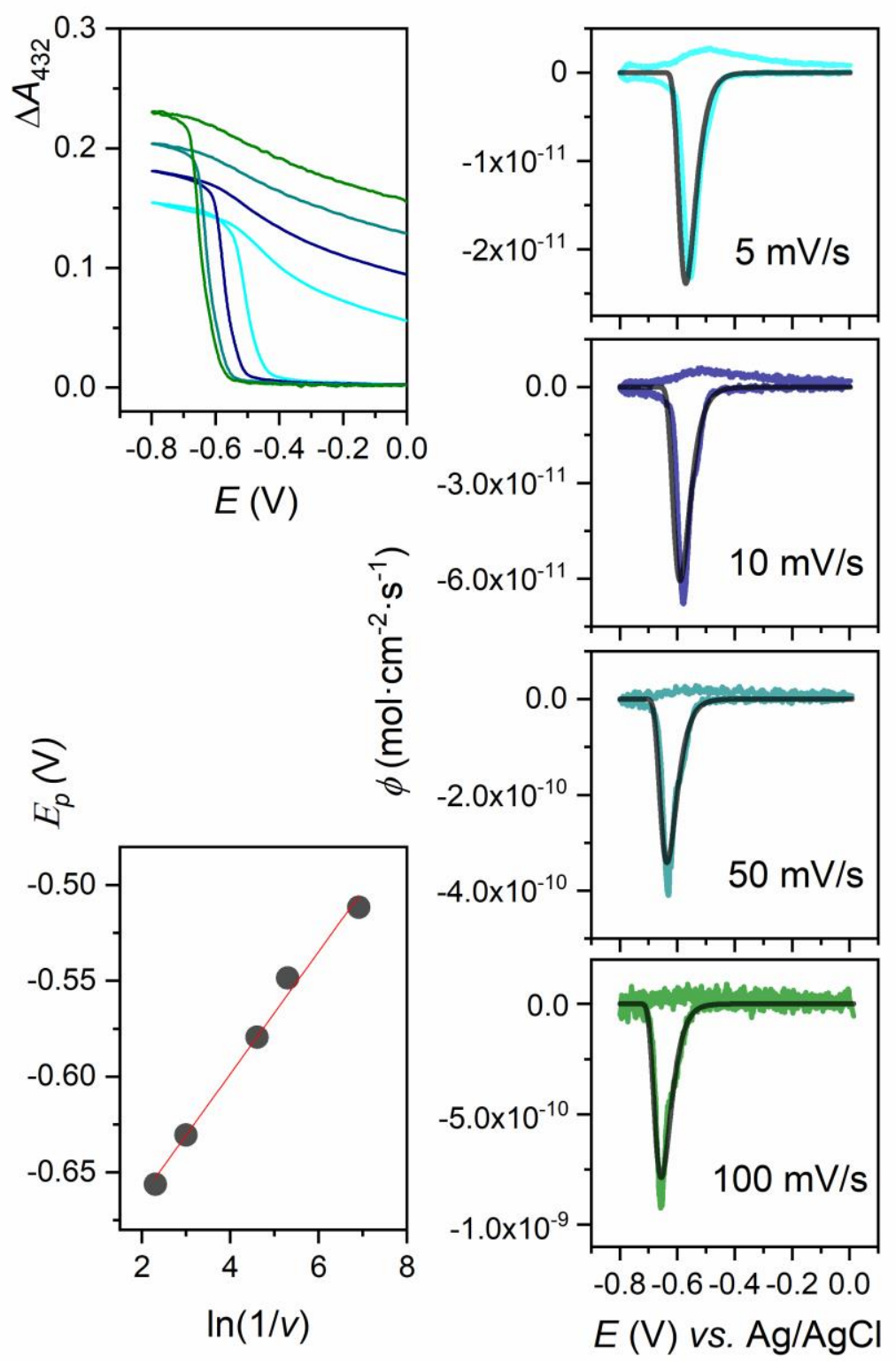

Figure S3. (Left, top) $\mathrm{CVA}_{432}$ monitored at a Mn-P/GLAD-TiO 2 electrode at scan rates of (cyan) 5, (navy) 10, (dark cyan) 50, and (olive) $100 \mathrm{mV} \cdot \mathrm{s}^{-1}$ in a deaerated $0.1 \mathrm{M} \mathrm{HEPES}+0.05 \mathrm{M} \mathrm{Na}_{2} \mathrm{SO}_{4}$ buffer solution at pH 7.0, and (right, top to bottom) corresponding DCVA 432 (with the same color code). The black curves correspond to best fits of the theoretical eq. 4 to the experimental data. Since a slow desorption of the porphyrin from the GLAD-TiO ${ }_{2}$ film was observed upon cycling the electrode at slow scan rates, the exact porphyrin surface coverage $\Gamma^{0}$ was re-evaluated for each scan rate from the total absorbance variation of the corresponding $\mathrm{CVA}_{432}$ (leading thus to the following $\Gamma^{0}$ values $0.37,0.47,0.53,0.61 \mathrm{nmol} \cdot \mathrm{cm}^{-2}$ when going from 5 to $100 \mathrm{mV} \cdot \mathrm{s}^{-1}$ ). For the best fitting of eq. 4 to the irreversible experimental DCVA peaks, the following parameters were used: $E_{\mathrm{CB}}=-0.78 \mathrm{~V}(\mathrm{vs}$. $\mathrm{Ag} / \mathrm{AgCl}$ at $\mathrm{pH} 7.0), \alpha=0.9$ and $k=272 \mathrm{~s}$ 1. (Left, bottom) Potential of the irreversible peak plotted as a function of $\ln (1 / v)$. The red solid line is the linear regression fit of eq. S1 reported below ${ }^{2}$ using $\alpha=0.9$ and $k=272 \mathrm{~s}^{-1}$.

$$
E_{p}=E_{C B}+\frac{R T}{\alpha F} \ln \left(\frac{R T}{\alpha F v} k\right)
$$




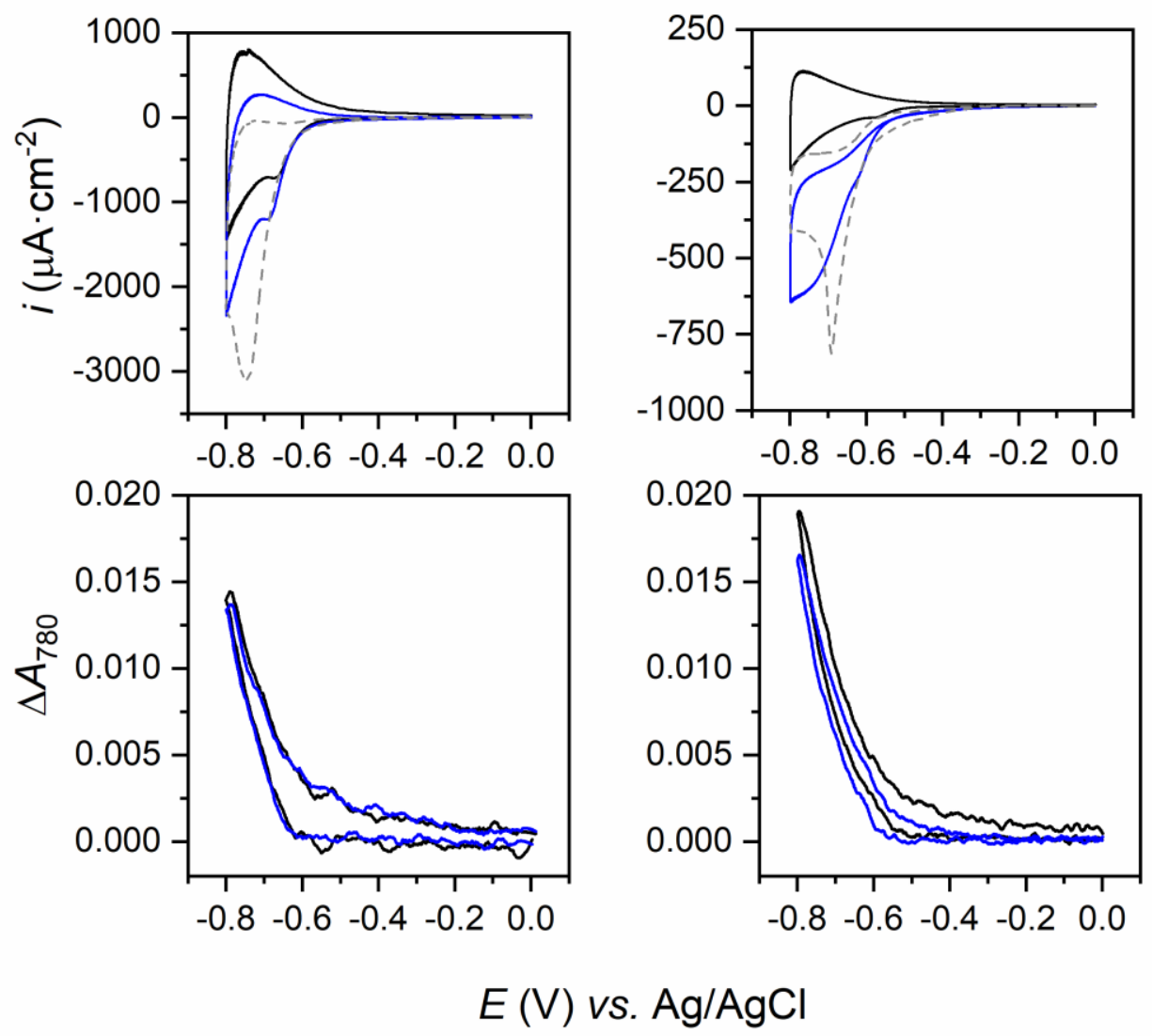

Figure S4. (Top) CVs and (bottom) $\mathrm{CVA}_{780} \mathrm{~S}$ simultaneously recorded at a bare $\mathrm{GLAD}-\mathrm{TiO}_{2}$ electrode under (solid blue) $\mathrm{O}_{2}$ or (solid black) argon atmospheres at scan rates of (left) 0.1 and (right) $0.01 \mathrm{~V} \cdot \mathrm{s}^{-1}$. The dashed grey curves on the upper graphs correspond to the CVs recorded under $\mathrm{O}_{2}$ atm. at the $\mathrm{Mn}$ $\mathrm{P} / \mathrm{GLAD}-\mathrm{TiO}_{2}$ electrode. 

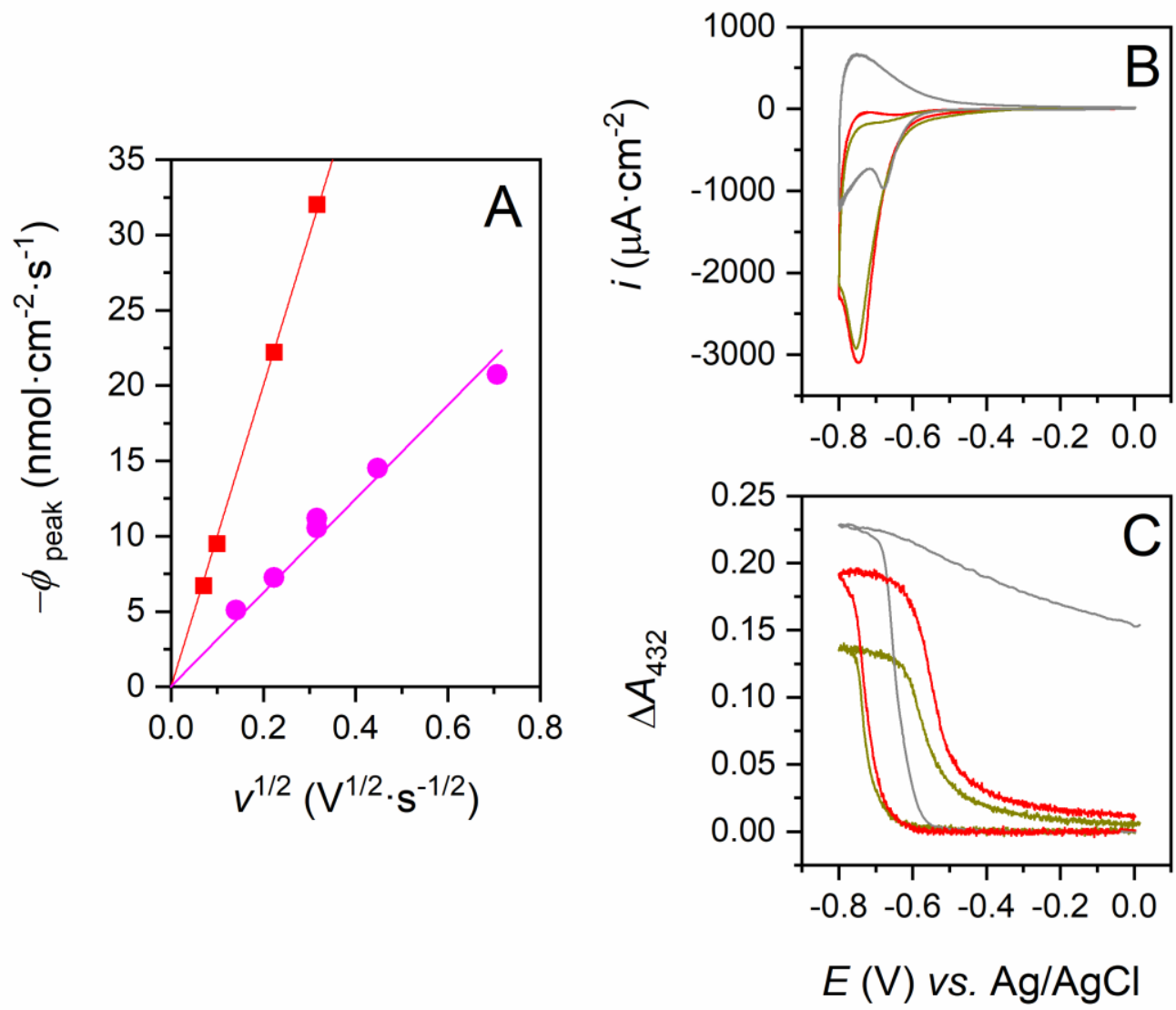

Figure S5. (A) Scan rate dependence of the catalytic peak intensity recorded at (red) Mn-P/GLAD-TiO and (magenta) Mn-P/GLAD-ITO electrodes. (B) $\mathrm{CVs}$ and (C) $\mathrm{CVA}_{432} \mathrm{~S}$ simultaneously recorded at $\mathrm{Mn}-\mathrm{P} / \mathrm{GLAD}-\mathrm{TiO}_{2}$ electrodes under (red and dark yellow) $\mathrm{O}_{2}$ or (grey) argon atmosphere at $100 \mathrm{mV} \cdot \mathrm{s}^{-1}$. The color code refers to $\mathrm{Mn}-\mathrm{P}$ surface coverage $\left(\Gamma^{0}\right)$ of (grey) $6 \times 10^{-10}$, (red) $4.7 \times 10^{-10}$, and (dark yellow) $3.5 \times 10^{-10} \mathrm{~mol} \cdot \mathrm{cm}^{-2}$. 

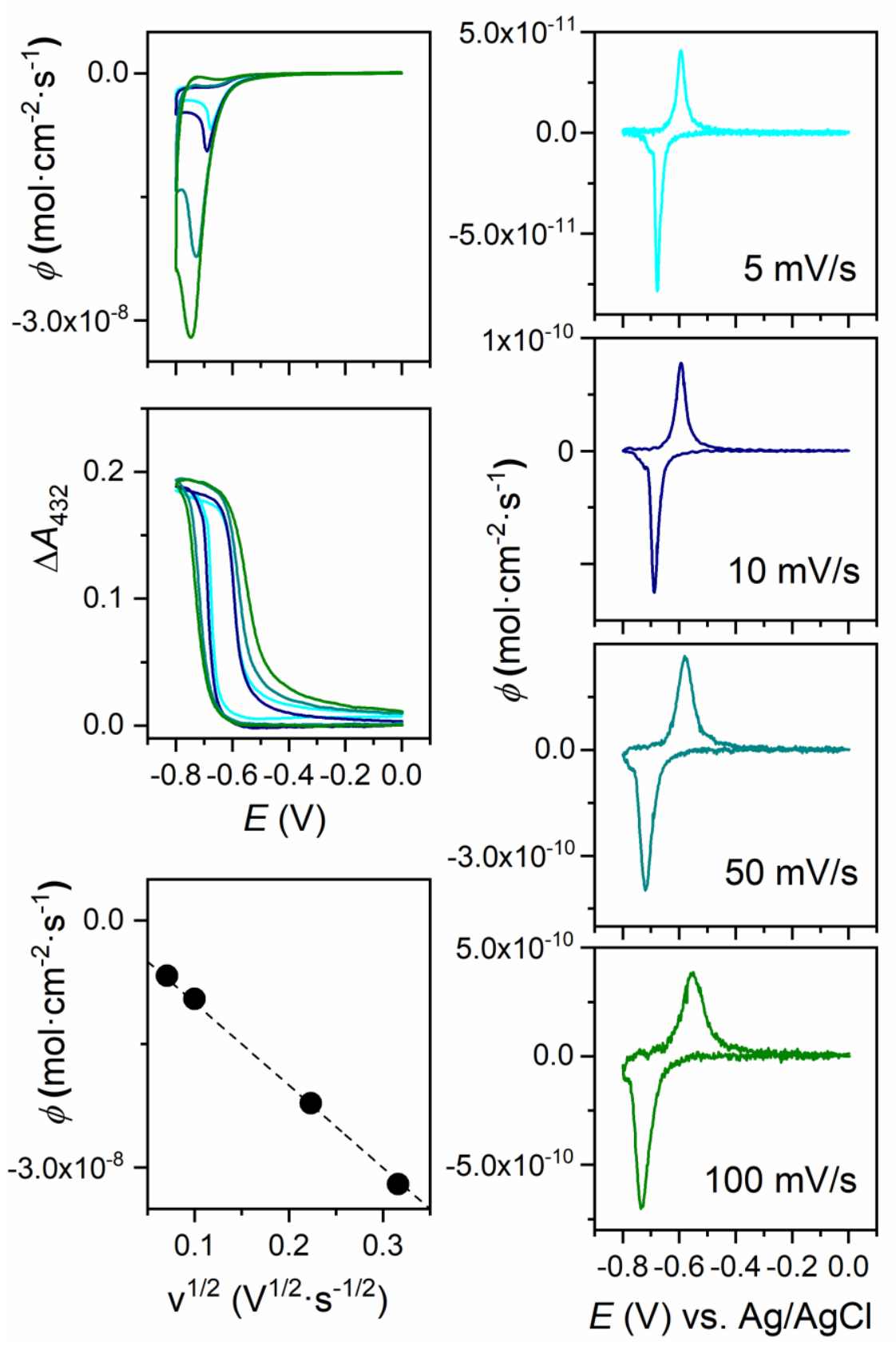

Figure S6. Left: (top) CVs and (middle) CVAs monitored at $432 \mathrm{~nm}$ at a Mn-P/GLAD-TiO ${ }_{2}$ electrode $\left(\Gamma^{0}=\right.$ $4.7 \times 10^{-10} \mathrm{~mol} \cdot \mathrm{cm}^{-2}$ ) at scan rates of (cyan) 5 , (navy) 10, (dark cyan) 50 and (olive) $100 \mathrm{mV} \cdot \mathrm{s}^{-1}$ under $\mathrm{O}_{2}$ atmosphere in a $0.1 \mathrm{M} \mathrm{HEPES}+0.05 \mathrm{M} \mathrm{Na}_{2} \mathrm{SO}_{4}$ buffer solution at $\mathrm{pH}$ 7.0. Right: corresponding DCVAs. Left: (bottom) intensity of the catalytic peak plotted as a function of the square root of $v$ and linear regression fit (slope: $-10^{-7} \mathrm{~mol} \cdot \mathrm{s}^{1 / 2} \cdot \mathrm{cm}^{-2} \cdot \mathrm{V}^{-1 / 2}$ ). 

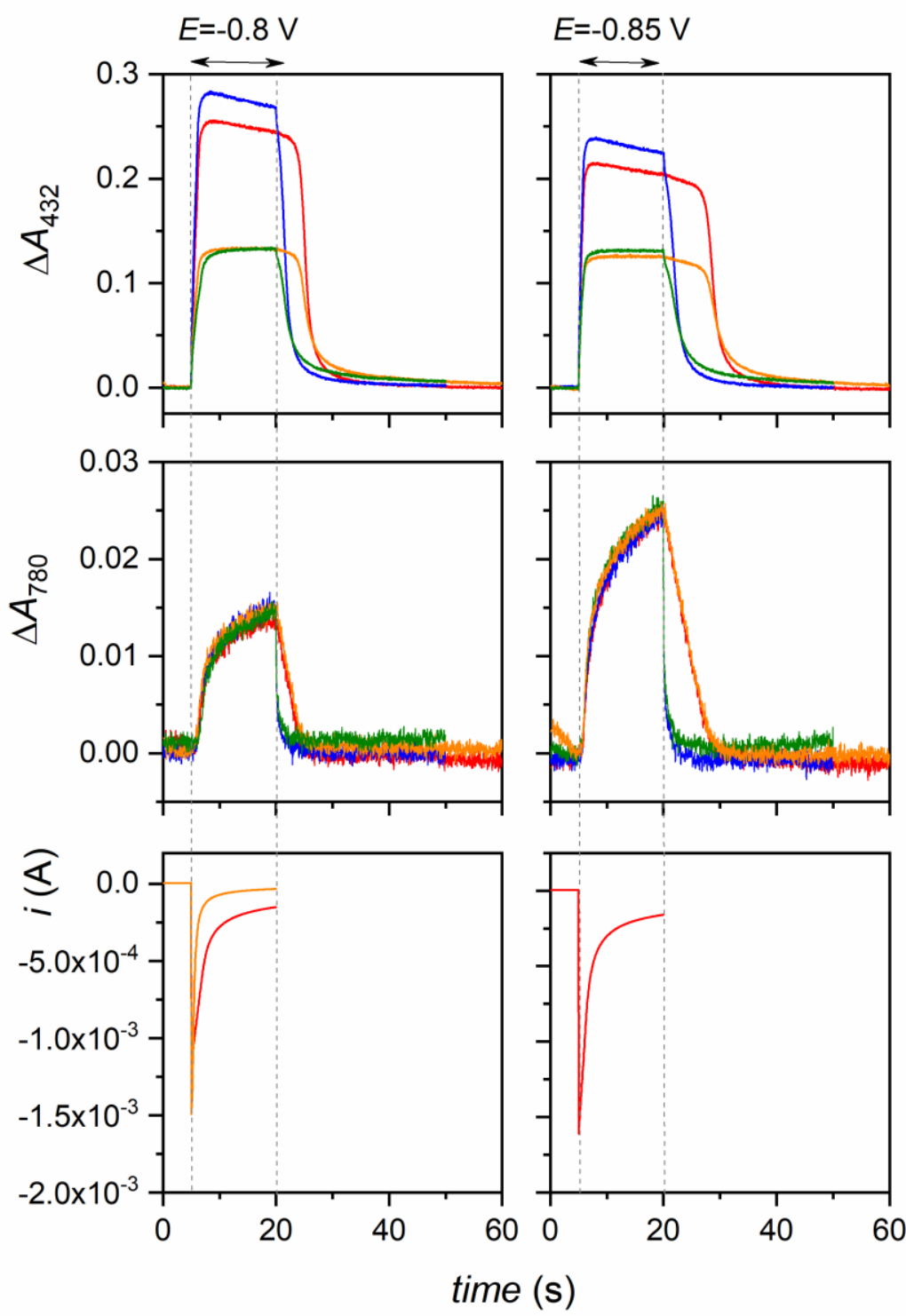

Figure S7. (Top and middle) chronoabsorptograms monitored at (top) $432 \mathrm{~nm}$ and (middle) $780 \mathrm{~nm}$ during the $15 \mathrm{~s}$ application of a cathodic potential of (left) $-0.8 \mathrm{~V}$ or (right) $-0.85 \mathrm{~V}$ (vs. Ag/AgCl) at a Mn$\mathrm{P} / \mathrm{GLAD}-\mathrm{TiO}_{2}$ electrode under $\mathrm{O}_{2}$ atmosphere. The bottom graphs show the chronoamperograms that were concomitantly recorded with the chronoabsorptograms shown on the top and middle graphs. At the end of the $15 \mathrm{~s}$ of reduction, the applied potential was either (blue and olive) stepped to an anodic value of $\mathrm{OV}$ or (red and orange) left to the open circuit potential value. The surface coverage of the Mn porphyrin was observed to slowly decrease with time (the values are reported in Table S1). Experiments were conducted at $25^{\circ} \mathrm{C}$ in a $0.1 \mathrm{M} \mathrm{HEPES}$ buffer $+0.05 \mathrm{M} \mathrm{Na}_{2} \mathrm{SO}_{4}$ at $\mathrm{pH}$ 7.0. The geometric electrode area was $0.5 \mathrm{~cm}^{2}$. 
Table S1. Estimation of the time required to $\left(t_{\text {empty }}\right)$ empty the $\mathrm{TiO}_{2}$ network or $\left(t_{1 / 2}\right)$ re-accumulate $50 \%$ of the oxidized catalyst after a $15 \mathrm{~s}$ reductive step performed at $E_{c a t}$ under $\mathrm{O}_{2}$ or air atmosphere.

\begin{tabular}{|c|c|c|c|c|c|c|}
\hline$E_{\text {cat }}(\mathrm{V})$ & Atm. & $\begin{array}{c}\Gamma_{\mathrm{e}-}^{\mathrm{a}} \\
\left.(\mathrm{nmol} \mathrm{cm})^{-2}\right)\end{array}$ & $t_{\text {empty }}{ }^{\mathrm{b}}(\mathrm{s})$ & $\begin{array}{c}\Gamma_{\mathrm{Mn}-\mathrm{P}} \mathrm{c} \\
(\mathrm{nmol} \mathrm{cm}-2)\end{array}$ & $E_{\text {an }}(\mathrm{V})$ & $t_{1 / 2}(\mathrm{~s})$ \\
\hline \multirow[t]{2}{*}{-0.75} & \multirow[t]{2}{*}{ air } & \multirow[t]{2}{*}{11} & & 0.65 & 0 & 4.2 \\
\hline & & & 19.3 & 0.65 & - & 20.2 \\
\hline \multirow[t]{6}{*}{-0.80} & \multirow[t]{4}{*}{$\mathrm{O}_{2}$} & \multirow[t]{4}{*}{15} & & 0.70 & 0 & 1.5 \\
\hline & & & 4.7 & 0.64 & - & 5.2 \\
\hline & & & & 0.35 & 0 & 2.0 \\
\hline & & & 4.7 & 0.35 & - & 5.4 \\
\hline & \multirow[t]{2}{*}{ air } & \multirow[t]{2}{*}{20} & & 0.42 & 0 & 5.2 \\
\hline & & & 35.1 & 0.40 & - & 38.3 \\
\hline \multirow[t]{4}{*}{-0.85} & \multirow[t]{4}{*}{$\mathrm{O}_{2}$} & \multirow[t]{4}{*}{25} & & 0.59 & 0 & 2 \\
\hline & & & 8.3 & 0.53 & - & 8.7 \\
\hline & & & & 0.34 & 0 & 2.4 \\
\hline & & & 8.3 & 0.33 & - & 9.3 \\
\hline
\end{tabular}

a Estimated from the maximal $\Delta A_{780}$ value assuming $\varepsilon_{780}=1000 \mathrm{M}^{-1} \cdot \mathrm{cm}^{-1}$

${ }^{b}$ Calculated assuming a constant re-oxidation rate of $3 \mathrm{nmol} \cdot \mathrm{cm}^{-2} \cdot \mathrm{s}^{-1}$ under $\mathrm{O}_{2}$ atmosphere or 0.57 under air (see main text for the rate estimation).

${ }^{\mathrm{c}}$ Estimated from the maximal $\Delta A_{432}$ value assuming $\varepsilon_{432}=380000 \mathrm{M}^{-1} \cdot \mathrm{cm}^{-1}$

\section{References}

1 L. J. Boucher, Coord. Chem. Rev., 1972, 7, 289-329.

2 C. Renault, L. Nicole, C. Sanchez, C. Costentin, V. Balland and B. Limoges, Phys. Chem. Chem. Phys., 2015, 17, 10592-10607. 